Graduate Institute of International and Development Studies

International Economics Department

Working Paper Series

Working Paper No. HEIDWP21-2017

\title{
Acquirers and Financial Constraints: Theory and Evidence from Emerging Markets
}

\author{
Rahul Mukherjee \\ The Graduate Institute, Geneva \\ Christian Proebsting \\ École Polytechnique Fédérale de Lausanne
}

Chemin Eugène-Rigot 2

P.O. Box 136

CH - 1211 Geneva 21

Switzerland

(C) The Authors. All rights reserved. Working Papers describe research in progress by the author(s) and are published to elicit comments and to further debate. No part of this paper may be reproduced without the permission of the authors. 


\title{
Acquirers and Financial Constraints: Theory and Evidence from Emerging Markets*
}

\author{
Rahul Mukherjee $^{\dagger} \quad$ Christian Proebsting ${ }^{\ddagger}$
}

November 15, 2017

\begin{abstract}
How do financial frictions shape the set of acquirers, how much they acquire, and how long they keep ownership? To address these questions, we develop a tractable model of M\&As whereby acquirers and targets emerge endogenously due to differences in liquidity. Financial crises lead to selection effects among acquirers that result in larger acquired stakes and more persistent ownership. We present evidence consistent with the predictions of the model in a dataset of domestic and cross-border M\&As from emerging markets. Financially constrained domestic firms in crisis-hit countries acquire 11-15\% more ownership. The survival rate of these acquisitions is $19-24 \%$ higher.
\end{abstract}

Keywords: domestic mergers and acquisitions; cross-border mergers and acquisitions; financial crisis; financial constraints; capital reallocation.

JEL Codes: F21, G01, G34.

\footnotetext{
${ }^{*}$ We thank, without implicating, Ron Alquist, Johannes Van Biesebroeck, Anusha Chari, Wei Cui, Giovanni Facchini, Olivier Jeanne, Nobu Kiyotaki, Damien Neven, Uday Rajan, Priya Ranjan, Linda Tesar and Farid Toubal for helpful conversations, and conference/seminar participants at EEA-ESEM, IHEID and the University of Michigan for comments. Mukherjee gratefully acknowledges the support of the Swiss National Science Foundation (Research Grant No. 172690). Alexandre Lauwers and Jingjing Xia provided excellent research assistance. An earlier draft of this paper circulated under the title "Survival of the Fittest: Corporate Control and the Cleansing Effect of Financial Crises".

${ }^{\dagger}$ Department of International Economics, Graduate Institute of International and Development Studies. Address: Maison de la Paix P1-619, 1202 Genève, Switzerland. E-mail: rahul.mukherjee@graduateinstitute.ch. Website:https://sites.google.com/site/rahulmkiheid/.

${ }^{\ddagger}$ Chair of International Finance, École Polytechnique Fédérale de Lausanne. E-mail: Christian.Probsting@epfl.ch. Website: https://sites.google.com/site/proebstingchristian/.
} 


\section{Introduction}

How do financial frictions and aggregate liquidity drive firms' acquisition decisions? A firm in financial distress might be bought up by a competitor, but only if that competitor is itself sufficiently liquid. In turn, financial crises lower the liquidity available to all firms in the economy and therefore have complex effects on which firms get acquired and who acquires them. In this paper, we study these effects and show that financial frictions shape the market for corporate control by both altering the set of target firms in need of liquidity and impinging upon an acquiring firm's acquisition decision.

In the last three decades we have witnessed tremendous growth in the global market for mergers and acquisitions (M\&As) - its volume stood at roughly 3.7 trillion USD in 2007, with cross-border M\&As totaling roughly 1.0 trillion USD in 2007 (UNCTAD, 2015) - which has brought together firms from countries with different levels of financial development. These firms are markedly distinct in their access to finance, with some being more vulnerable to country- or region-wide financial crises than others. Recent research shows that these differences do indeed affect which firms are acquired (Aguiar and Gopinath, 2005; Acharya, Shin and Yorulmazer, 2011a,b; Alquist, Mukherjee and Tesar, 2016; Alquist et al., 2017), what form of financing, such as cash versus credit lines, are used for acquisitions (Almeida, Campello and Hackbarth, 2011), as well as the post-acquisition performance of firms (see Erel, Jang and Weisbach, 2014, among others). These studies, by and large, focus only on the role of financial frictions for potential targets of an acquisition and assume that acquiring firms always are sufficiently liquid. ${ }^{1}$ Sparked by the empirical relevance of within-border acquisitions, our paper extends this work to consider the case where not only the target firm, but also the acquirer themselves face liquidity problems, potentially simultaneously with their target in times of a country-wide financial crisis. By doing this, our paper has two main contributions, one theoretical and one empirical.

Our first contribution is to develop a simple analytical framework in which both financially constrained and financially unconstrained acquirers engage in M\&As in a setting of financial underdevelopment. In our model, all firms in the financially underdeveloped economy face borrowing constraints. Some of these firms exit because they lack sufficient liquidity to operate. Other firms with more internal financial resources and sufficient borrowing capacities can step in to buy their assets and thus prevent liquidation. We label these acquisitions "low-value" acquisitions because they take place even in the absence of technological synergies between the two firms. "High-value" acquisitions, in contrast, involve those acquirer-target matches that are expected to be profitable thanks to technological synergies and independent of the target's liquidity position. In this framework, we study the implications of an aggregate negative financial shock that tightens the borrowing constraints of all firms in the economy, including potential domestic acquirers, but excluding potential foreign acquirers. We analyze the shock's implications

\footnotetext{
${ }^{1}$ Almeida, Campello and Hackbarth (2011) is a notable exception that we discuss later.
} 
for two metrics: the ownership structure chosen in an M\&A and for how long an acquiring firm keeps its ownership shares before reselling them. While studying the determinants of firm ownership is interesting in its own right, our focus on these two metrics is motivated by an extensive prior literature, both theoretical and empirical, showing that ownership structure and its evolution over time is a key determinant of a number of firm level variables. ${ }^{2}$ Throughout our analysis, we contrast the behavior of domestic acquirers, who are subject to the financial shock, to the behavior of foreign, financially unconstrained acquirers in order to highlight the role of financial constraints in a firm's acquisition decision.

To study the effect on the share acquired in an M\&A, we augment our model with a feature that is consistent with recent evidence from emerging market acquisitions: Higher value acquirer-target synergies are associated with larger, possibly controlling, or full stakes acquired in target firms (Chari, Ouimet and Tesar, 2010; Alquist et al., 2017). ${ }^{3}$ We first show that a negative financial shock tends to raise the share of low-value, purely liquidity-driven acquisitions in the total number of acquisitions, simply because a larger proportion of potential target firms face liquidity shortages. ${ }^{4}$ This first channel has been studied before, resulting in papers such as Aguiar and Gopinath (2005), Acharya, Shin and Yorulmazer (2011b) and Alquist, Mukherjee and Tesar (2016). Our model highlights a second, counteracting channel based on financial frictions on the acquirer's side: Since an acquisition with higher expected gains from synergies relieves the joint, forward-looking borrowing constraint of the acquirer-target pair, an aggregate financial shock that tightens financial constraints for both acquiring and target firms will result in only the highest synergy acquisitions taking place. This leads to proportionally more acquisitions with real value gains (high-value acquisitions) undertaken by domestic acquirers in times of aggregate financial stress. Coupled with the above-mentioned evidence about a positive relationship between stake size and the value gains in acquisitions, this translates into larger stakes acquired by domestic acquirers, as well a greater likelihood of completing majority or full acquisitions. We show that this selection effect is absent in the limiting case when acquiring firms do not face borrowing constraints. That is, while we expect foreign firms to acquire smaller shares during financial crises, domestic firms will, on average, acquire larger stakes, or at least, we should observe a smaller reduction in their acquired share, depending on the strength of the selection effect.

Next, we show that our model also has opposite predictions for domestic and foreign acquirers regard-

\footnotetext{
${ }^{2}$ Examples include agency costs (Ang, Cole and Lin, 2000), the degree of technology transfer (Hanousek and Kočenda, 2017), value gains from an acquisition (Chari, Ouimet and Tesar, 2010) as well as their distribution between the target and acquirer shareholders (Asiedu and Esfahani, 2001), and the incentives of the firm's owners to apply their technological or management resources (Asiedu and Esfahani, 2001). By extension, the dynamics of the ownership structure of a firm exerts influence on the evolution over time of a number of the above variables, as well as being informative about the performance of the acquisition itself (Hoskisson, Johnson and Moesel, 1994; Lee and Madhavan, 2010).

${ }^{3}$ This could be due to the presence of intangible assets in a setting of imperfect contract enforceability as in Chari, Ouimet and Tesar (2010), or local inputs in the production process as in Alquist et al. (2017).

${ }^{4} \mathrm{~A}$ similar channel, whereby financial crises may increase the share of cross-industry acquisitions performed by foreign acquiring firms has been studied recently by Alquist, Mukherjee and Tesar (2016).
} 
ing the persistence of ownership stakes, i.e. the rate at which acquisitions are divested. We augment our model by an additional time period in which firms can resell their assets acquired in the initial, financialcrisis period. In our model, divestiture rates vary with aggregate conditions for two reasons. First, when the matches between acquirers and targets are low-value and liquidity-driven, they are reversed as soon as aggregate conditions improve. This leads to larger "flipping" rates in the aftermath of financial crises. This channel, which we call "normal" flipping, has been emphasized so far in the literature by papers such as Acharya, Shin and Yorulmazer (2011b) and Alquist, Mukherjee and Tesar (2016). Our model introduces a second, novel channel that is only present for domestic acquirers that face financial frictions: Acquirers may also divest acquisitions when they themselves run into liquidity problems at future dates, a channel that we call "forced" flipping. We show-assuming some persistence in firm liquidity across periods-that the forced flipping motive is less prevalent in the shock cohort of constrained acquirers. This lowers average flipping rates for domestic acquirers in the aftermath of financial crises. Intuitively, this happens because the high-liquidity firms that were able to complete acquisitions in bad times, are also less likely to run into liquidity problems at future dates and therefore be forced to divest. Note that this channel, once again, works exclusively through a selection effect of having relatively more liquid acquirers in the crisis cohort of constrained acquirers, rather than any changes in individual firm-level flipping decisions.

The empirical literature so far has mostly focused on identifying the effects of financial frictions on the target side. In contrast, our interest lies in trying to carefully distinguish between these and the effects of acquirer-side frictions. However, since an aggregate shock hits all firms, i.e., both acquirers and targets, a simple empirical comparison between the ownership structures chosen by acquirers during crisis versus normal times, as well as the subsequent divestiture rates of the crisis cohort of acquisitions, will in general confound the effect of the crisis on acquirers with that of the effect of the crisis on targets. Hence, we adopt a difference-in-difference strategy in deriving predictions from the model that we then test in the data. Since foreign acquirers from developed markets face the same pool of target firms as the domestic acquirers, yet do not face the effect of the crisis themselves, the differential effect of the crisis on the ownership structures chosen by foreign versus domestic acquiring firms, as well any such double differentials in divestiture rates, should be informative about the effect of the crisis on financially constrained acquirers. This idea formed the basis of our main theoretical predictions, and informs the design of our empirical analysis. In particular, we next test our two theoretical predictions that (i) the average share of equity acquired by constrained (domestic) acquirers, as compared to unconstrained (foreign) acquirers should rise during financial crises, driven by an increase in majority or full acquisitions, and that (ii) the divestiture rates for domestic acquisitions should be relatively lower for the crisis cohort of domestic acquisitions (in relation to unconstrained foreign acquisitions).

We test these predictions of the model using Thompson-Reuters SDC data for about 28,000 domestic and cross-border M\&As in sixteen of the largest markets for corporate control in emerging economies 
between 1990 and 2007. We focus on emerging market targets because we expect domestic firms there to conform more closely to the constrained firms of the model, while the choice of sample period is guided by the need to have a financially unconstrained group of foreign acquiring firms, which is the case only for the pre-2007 sample. Due to the structure of our hypotheses, which involve comparisons of two kinds of acquisitions (relatively financially constrained and unconstrained acquisitions, proxied by those made by domestic and foreign acquiring firms, respectively), across two macroeconomic regimes (normal times and adverse financial shocks, the latter proxied by the plausibly exogenous occurrence of country-specific banking crises), we employ a difference-in-difference approach. Using linear regressions and survival analysis techniques, we find strong evidence in favor of all the main predictions of the model. In particular, we find that financially constrained domestic firms in the crisis-hit country acquire between 11-15\% more ownership and are 15-18\% more likely to take majority stakes than their unconstrained foreign counterparts. Such ownership is also more likely to be persistent: The survival rate of a domestic acquisition is between $19-24 \%$ higher in the crisis cohort. We find that these empirical results are robust to a battery of checks that include, among others, alternative definitions of aggregate financial shocks, the inclusion of macroeconomic variables to control for normal business cycle variation in acquisition activity, different fixed effects combinations, and non-linear estimation procedures.

Our paper builds on a recent literature on the financial determinants of M\&As, and in particular, the findings of Almeida, Campello and Hackbarth (2011) and Alquist, Mukherjee and Tesar (2016). Almeida, Campello and Hackbarth (2011) show that when a key motivation of mergers is to reallocate financial resources from liquid to illiquid firms, pledgability issues may make it optimal for high net worth firms to use discretionary credit lines to finance mergers. They also provide empirical evidence in favor of such a role using a sample of domestic deals from the United States. In contrast to Almeida, Campello and Hackbarth (2011) our theoretical focus is on the choice of ownership, its evolution, and the aggregate implications of selection effects, while our empirical analysis uses domestic and cross-border deals from emerging markets. Our work also builds on Alquist, Mukherjee and Tesar (2016), who look at so-called fire-sale foreign direct investment in a model where all target firms are credit constrained and all acquiring firms are unconstrained. In contrast to their paper, we develop a more general, yet tractable framework in which all firms, acquirers or targets, may be financially constrained, with important consequences. In addition, our empirical emphasis is on the response of financially constrained domestic firms, and as such, we use foreign firms only as a benchmark group of unconstrained acquirers to isolate the effects of acquirer versus target financial constraints. ${ }^{5}$ In related work, Erel, Jang and Weisbach (2014) provide evi-

\footnotetext{
${ }^{5}$ Alquist, Mukherjee and Tesar (2016) emphasize the industry composition of acquisitions. In their model matches between firms in the same industry are more productive and financial crises lead to more inter-industry acquisitions. Our approach in this paper is more general in that we do not assume any particular industry patterns in the gains from acquisitions. In addition, Alquist, Mukherjee and Tesar (2016) only model the decision of an unconstrained foreign acquiring firm since their focus is on foreign direct investment. Earlier research (see Aguiar and Gopinath, 2005; Acharya, Shin and Yorulmazer, 2011b) focused on the
} 
dence that both foreign and domestic acquisitions ease financial frictions in target firms in a large sample of European acquisitions. They find that the investment levels of the target firms increase significantly following an acquisition. These findings are consistent with our assumption that part of the gains from acquisitions arise out of acquirers relaxing the borrowing constraints of the targets. Other recent papers such as Chari, Ouimet and Tesar (2010) and Wang and Wang (2015) also document similar financial gains from acquisitions. From an empirical point of view, while domestic divestitures have been widely studied using US data (Ravenscraft and Scherer, 1991; Kaplan and Weisbach, 1992; Bergh, 1997), and for foreign acquisitions in emerging markets (Acharya, Shin and Yorulmazer, 2011b; Alquist, Mukherjee and Tesar, 2016), few papers have focused on documenting and explaining this phenomenon for the large set of domestic acquisitions in emerging markets, as we do. More broadly, our paper contributes to the literature on M\&As that seeks to explain specific characteristics of acquirer-target matches, for example, RhodesKropf and Robinson (2008), who build and test a model of assortative matching in M\&As based on firm valuations.

Last but not least, the main mechanism in our paper is a selection effect based on firm-level liquidity and the value gains from an acquisition. The latter can take many forms, including an increase in productivity or wages in the acquired firm. Hence, our paper also speaks to a large literature in macroeconomics that deals with the cleansing effect of recessions, i.e. the process by which the least productive firms in the economy are forced to exit during a recession, leading to aggregate effects on productivity. ${ }^{6}$ This literature, however, has generally ignored the existence of the market for corporate control where distressed firms may be acquired. In the concluding section we therefore discuss some implications of our results for macroeconomic models that analyze the allocative effects of aggregate shocks.

surge of foreign acquisitions and a concurrent decline in domestic acquisitions and portfolio investment during crisis episodes in emerging economies, as well as the relationship between acquisition prices and firm liquidity.

${ }^{6}$ This literature has explored several mechanisms in connection with the cleansing effect, related to labor markets (Caballero and Hammour, 1996), entrepreneurial credit constraints (Holtz-Eakin, Joulfaian and Rosen, 1994), and the contribution of new producers' productivity advantages and entry (Foster, Haltiwanger and Syverson, 2008). Here, the closest paper to ours is Osotimehin and Pappadà (2015), who look at how credit constraints influence the cleansing effect of recessions in a theoretical model of firm dynamics. In a similar vein, our paper is also related to the literature that studies the reallocation of capital and other resources over the business cycle. Eisfeldt and Rampini (2006) explore the procyclicality of capital reallocation among firms, and the apparent countercyclicality of the benefits from reallocation. Their analysis suggests that the cost of capital reallocation needs to be strongly countercyclical to rationalize the observed joint cyclical properties of reallocation and productivity dispersion. Cui (2014) develops a dynamic general equilibrium model where partial capital irreversibility generates delays in capital reallocation during periods when credit conditions are tighter and lowers aggregate productivity. A recent strand of this literature uses disaggregate data to quantify resource misallocation during crises. Oberfield (2013) and Sandleris and Wright (2014) provide evidence from the 1982 Chilean economic crisis and the 2001 Argentine crisis, respectively, of a decline in the efficiency of resource allocation within and across sectors during these crises. These papers, however, do not address the question of reallocation of capital across firm boundaries through the M\&A market. 


\section{A Model of Selection Effects in M\&As}

This section presents a simple model where financially constrained firms can become targets of acquisitions, and acquire other firms themselves if they have enough resources. We focus our analysis on the averages of two readily observable metrics - what fraction of a firm is acquired and divestiture rates that have been studied in the M\&As literature. The main mechanism that drives our results are selection effects based on the financial liquidity (in turn determined by an economy-side pledgability constraint and firm-level expected future profits) of both acquirers and targets, and the degree of operational synergies arising from a match between them.

We start in Section 2.1 by describing the environment and the problems of the acquiring and target firms. In Section 2.2 we conduct a simple comparative static exercise, which is an aggregate tightening of financial constraints, for example, due to a systemic banking crisis. We show that such an episode reduces the average acquired share for unconstrained acquirers that are unaffected by the crisis, but likely increases it for constrained acquirers. We also identify an extensive and an intensive margin to pinpoint to the sources of this aggregate change. The extensive margin refers to the increase in the share of highvalue acquisitions (defined later) in the total number of acquisitions. The intensive margin refers to the change in the distribution of ownership shares within low- and high-value acquisitions. We then extend our model in Section 2.3 to analyze the subsequent resale of acquired assets. Our main finding here is that aggregate financial shocks lead to higher subsequent flipping rates for unconstrained acquirers, but lower flipping rates for potentially constrained acquirers. We conclude this section by showing that our hypotheses are also quantitatively important in a calibrated version of our model.

\subsection{Two-Period Model Setup}

The economy is populated by a continuum of firms. Firms in the baseline version of the model last for two periods 0 and 1, and differ in their expected gross profits in period 1. Firms borrow in period 0 to finance their production in period 1 and are able to pledge a certain fraction of their expected gross profits to take out loans.

\subsubsection{A Firm's Problem Without Acquirers}

This section describes a firm's optimization problem in the absence of any acquisitions. To produce in period 1, all firms have to pay an upfront cost, $b$. Firms differ in their expected period 1 (gross) profits, $y_{i}$, which is i.i.d. across firms. Here, $i$ indexes a particular firm and we think of this firm as a potential target of an acquisition. We later introduce the subscript $j$ to index potential acquirers. We assume that $y_{i}>b$ for all $i$ so that all firms prefer production to non-production. 
Firms' initial endowment is 0 , so that firms have to take out a loan to pay for the upfront cost $b .{ }^{7}$ Firms are restricted in the loan size they can take out. In particular, the loan size cannot exceed a certain fraction $\tau$ of gross expected profits:

$$
b \leq \tau y_{i}
$$

So $\tau$ measures the degree of credit frictions in the economy, which we assume to be the same across all firms. In an economy without credit frictions, $\tau=1$, whereas $\tau=0$ implies that firms cannot borrow to pay for the upfront costs. One can interpret $\tau$ as a measure of the maximum 'debt-to-value' ratio because $b$ corresponds to a firm's debt, and $y_{i}$ is a firm's expected profits that is available to pay off the debt. ${ }^{8}$ When we later discuss the effect of financial crises on acquired shares and divestiture rates, we model financial crises through changes in $\tau$.

If a firm lacks the capacity to pay for the upfront cost - that is if $y_{i}<\frac{b}{\tau}-$ it cannot produce in the second period and the value of the firm is 0 . These firms either immediately exit the market or become targets of acquisitions. Market exit of this kind can be interpreted as inefficient liquidation of the firm since the firm would always prefer production to non-production. If a firm's expected profits are high enough, it can secure a loan and produce, which raises its value by the expected profit net of the upfront costs, $y_{i}-b$. These firms can stay in the market as stand-alone entities, can be targets of acquisitions or can be acquirers themselves. The total value of a (potential target) firm $i$ can then be summarized as

$$
V_{i}^{t a r}= \begin{cases}0 & \text { if } y_{i}<\frac{b}{\tau} \\ y_{i}-b & \text { if } y_{i} \geq \frac{b}{\tau}\end{cases}
$$

We now discuss the acquisition problem of potential acquirers, indexed by $j$.

\subsubsection{Acquisition Decision and the Target's Financial Position}

Any pair of firms, denoted by $i$ for a target and $j$ for an acquirer, from the population described above can potentially meet in the market for corporate control. We assume that $i$ and $j$ are randomly matched

\footnotetext{
${ }^{7}$ In an earlier version of this paper, we considered differences in a firm's initial endowment. Under the assumption that endowments and gross profits are independently distributed, the results are not affected by this additional dimension of heterogeneity.

${ }^{8}$ The form of the borrowing constraint captures a common prediction from models of limited contract enforcement: The amount of credit is limited by the borrower's expected profits. That is, the debt limit is forward-looking, as e.g. in Albuquerque and Hopenhayn (2004) or Kehoe and Perri (2002). This forward-looking feature of the debt limit is a crucial element of our model. An alternative would be to model credit frictions through borrowing constraints that restrict the amount of debt to a borrower's current wealth (see Bernanke and Gertler, 1989; Kiyotaki and Moore, 1997; Buera, Kaboski and Shin, 2011, for example). Brooks and Dovis (2013) provide an empirical analysis of these two types of credit frictions and find evidence in favor of the forward-looking debt limit, which we adopt here.
} 
in this market. As soon as they are matched, they draw a synergy parameter net of acquisition costs, $\phi_{i, j}$, which is i.i.d. across matched pairs and assumed to be strictly positive. When a firm acquires a target, the target firm produces next period and its expected net profits $y_{i}-b$ change by the factor $\phi_{i, j}$. The value of an acquired target firm $i$ to an acquirer $j$ is then

$$
V_{i, j}^{a c q}=\phi_{i, j}\left(y_{i}-b\right)
$$

Note that $\phi_{i, j}$ can potentially be less than unity, which implies that acquisitions can be value-destroying, net of the costs of acquiring (Moeller, Schlingemann and Stulz, 2005). An acquisition takes place under two conditions: i) its surplus is positive and ii) it is feasible. Note here that while we do not explicitly model the process by which acquiring firms search for targets, the matching process described is quite general in that it does not make any assumptions about which firms (say based on size, productivity, Tobin's $Q$ etc.) end up in a match, except that they draw a stochastic match quality parameter.

The surplus is the difference between the value of the acquired firm after and before the acquisition, i.e. $V_{i, j}^{a c q}-V_{i}^{\text {tar }}$ :

$$
S_{i, j}= \begin{cases}S_{i, j}^{\text {cons }}=\phi_{i, j}\left(y_{i}-b\right) & \text { if } y_{i}<\frac{b}{\tau} \\ S_{i, j}^{\text {uncons }}=\left(\phi_{i, j}-1\right)\left(y_{i}-b\right) & \text { if } y_{i} \geq \frac{b}{\tau}\end{cases}
$$

Figure 1 shows the zero-surplus line $S=0$ as a function of the synergy parameter $\phi_{i, j}$ and the target firm's expected profit $y_{i}$. We denote the levels of $\phi_{i, j}$ that solve $S^{\text {cons }}=0$ and $S^{\text {uncons }}=0$ by $\phi^{l o}$ and $\phi^{h i}$ :

$$
\phi^{l o}=0<\phi^{h i}=1
$$

For $\phi_{i, j}>\phi^{h i}=1$, an acquisition always generates positive surplus because the net benefits from the resulting technological synergies are positive. This is true irrespective of the target firm's profits $y_{i}$ and the tightness of the borrowing constraint. These acquisitions occur in the region above the line $F F^{\prime}$. We refer to them as "high-value" acquisitions. If the two firms draw a synergy parameter $\phi^{l o} \leq \phi_{i, j}<\phi^{h i}=1$, technological synergies are not sufficient to make an acquisition profitable. However, if the target firm is financially constrained (i.e. its expected profits are too low, $y_{i}<\frac{b}{\tau}$ ), so that the firms would be otherwise liquidated, an acquisition generates additional benefits from relaxing the borrowing constraint of the target and is therefore profitable. Firm pairings with $\phi^{l o} \leq \phi_{i, j}<\phi^{h i}$ and $y_{i}<\frac{b}{\tau}$ (within the rectangular area $A B C F$ ) are therefore profitable, and are referred to as "low-value" acquisitions.

Firms in the region to the bottom left of $A B C^{\prime}$ are forced to exit because they cannot pay the fixed cost of operating in period 1 , yet their realized $\phi_{i, j}$ with the acquirer they have been randomly paired with is too low for an acquisition to be profitable. The firms to the right of $C^{\prime} C F^{\prime}$ remain stand-alone 


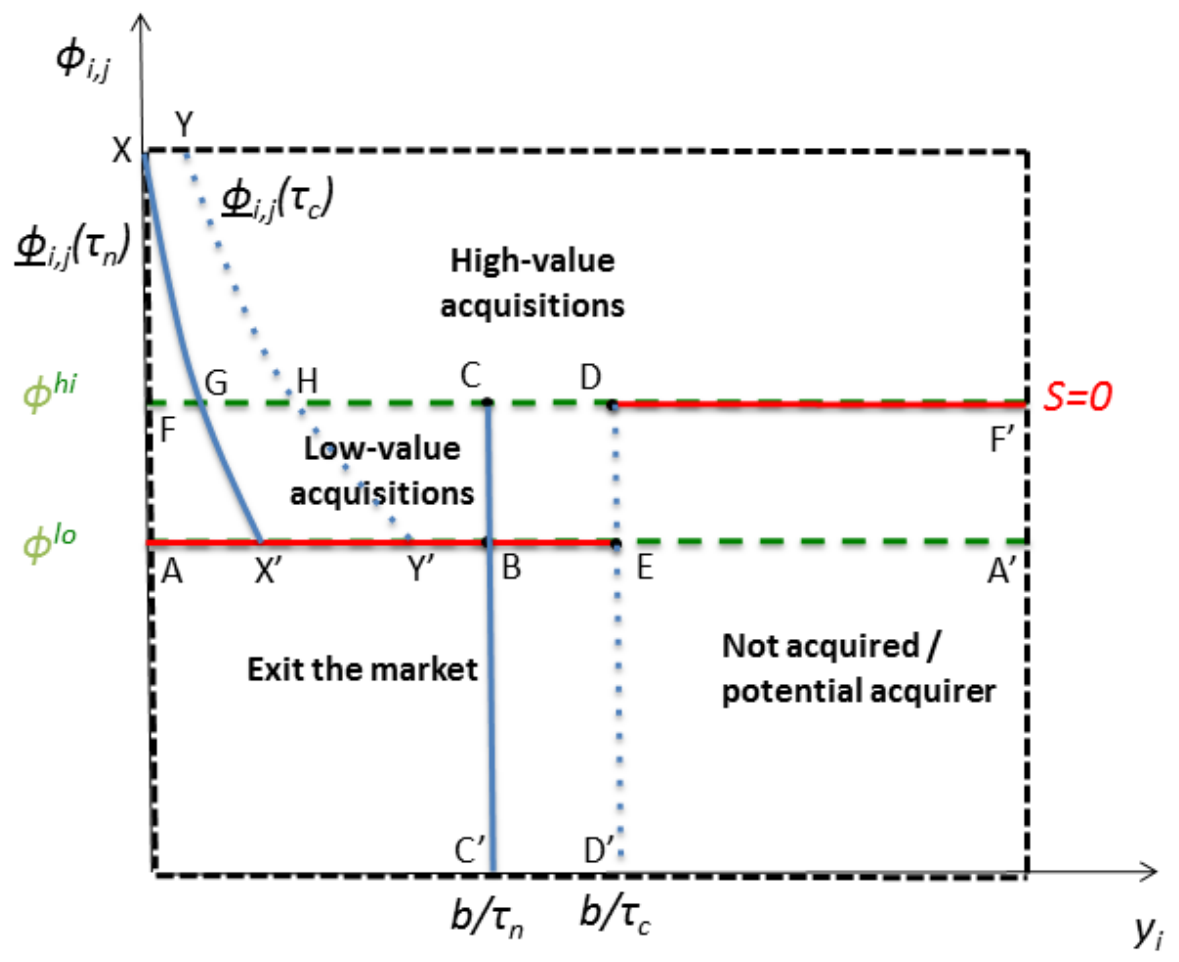

Figure 1: Acquisitions

Notes: Shows the range of values for the target's net profits, $y_{i}$, that define low- and high-value acquisitions for acquisitions during normal and crisis periods. These ranges are $\underline{\phi}_{i, j}^{-1} \leq y_{i} \leq \frac{b}{\tau}$ for low-value and $y_{i} \geq \underline{\phi}_{i, j}^{-1}$ for high-value acquisitions, with the subscript on the $\tau$ indicating (n)ormal or (c)risis periods, and $\underline{\phi}_{i, j}^{-1}$ being the inverse of the function defined in equation (2.5) solved for $y_{i}$.

entities or become acquirers themselves: Neither are they financially constrained, nor have they drawn a $\phi_{i, j}$ high enough (>1) for them to be acquired on the basis of technological synergies alone.

\subsubsection{Acquisition Decision and the Acquirer's Financial Position}

The previous section describes how the surplus generated from an acquisition depends both on the synergies it creates and on the financial position of the target firm. However, besides generating a positive surplus, an acquisition also has to be feasible. This depends on the acquirer's financial position.

Financially Constrained Acquirer. Acquirers with low realizations of $y_{j}$ are potentially constrained. Like their targets, they face borrowing constraints, which reduces their ability to perform acquisitions. 
As a consequence, some acquisitions that would generate a positive surplus do not take place because the acquirer himself lacks the liquidity to finance the acquisition.

Since the acquirer as well as the target are financially constrained, we need to consider both of their borrowing constraints and keep track of both of their expected net profits post-acquisition, which are $y_{j}$ and $\phi_{i, j} y_{i}$, respectively. Generally, the borrowing constraint for the post-acquisition entity states that total upfront costs, $2 b$, cannot exceed some value $2 \tau B\left(\phi_{i, j} y_{i}, y_{j}\right)$ :

$$
b \leq \tau B\left(\phi_{i, j} y_{i}, y_{j}\right)
$$

Here, the function $B$, together with $\tau$, determines this upper limit, which we assume to positively depend on both the acquirer's profits, $y_{j}$, and the target's post-acquisition profits, $\phi_{i, j} y_{i}$. Assuming that this function is invertible in $\phi_{i, j} y_{i}$, it is convenient to denote the minimum values for $\phi_{i, j}$ and $y_{i}$ that satisfy this borrowing constraint as $\underline{\phi}_{i, j}\left(y_{i}, y_{j}\right)$ and $\underline{y}_{i}\left(\phi_{i, j}, y_{j}\right)$. We also refer to this joint borrowing constraint as a feasibility constraint in the context of an acquisition.

The impact of this feasibility constraint on acquisitions is illustrated in Figure 1. In addition to the synergy cut-offs that characterize the set of points where acquisitions are profitable (for a given $y_{j}$, the area on the $\phi_{i, j}-y_{i}$ plane bounded below by $A B C F^{\prime}$ in Figure 1), there is now an additional downward sloping curve $X X^{\prime}$ describing the joint borrowing constraint of the target firm and the acquirer. $X X^{\prime}$ shows the minimum target's expected profits, $\underline{y}_{i}$, for each $\phi_{i, j}$ (or the minimum synergy level $\underline{\phi}_{i, j}$ at each level of $y_{i}$ ) that makes acquisitions feasible, given an acquirer's expected profits, $y_{j}$, and aggregate financial conditions, $\tau$. For a given $\phi_{i, j}$ of a match, only acquisitions to the right of $X X^{\prime}$ can potentially take place, even if they are profitable, because the acquirer himself faces financial constraints. The negative slope of the $X X^{\prime}$ can be understood as follows. Because low $\phi_{i, j}$ acquisitions have lower expected profits, the feasibility constraint is tighter for these acquisitions. These acquisitions therefore need larger target firm expected profits, $y_{i}$, to make them feasible. The acquirer's expected profits, $y_{j}$, and aggregate financial conditions, $\tau$, act as "shifters" for the $X X^{\prime}$ curve. For acquirers with higher expected profits $y_{j}$, the curve $X X^{\prime}$ shifts down and lowers the cut-off value of the synergy parameter $\phi_{i, j}$. For high enough $y_{j}$ the curve $X X^{\prime}$ crosses point $A$, so that the impact of the acquirer's financial constraint is no longer felt. A higher $\tau$ has an analogous effect on $X X^{\prime}$.

Figure 1 illustrates that the feasibility constraint restricts the mass of both low- and high-value acquisitions that a constrained acquirer can actually complete upon being matched with a target. For an acquisition by a constrained firm to take place, the following two conditions have to be met: i) it generates positive surplus, i.e., $\phi_{i, j} \geq \phi^{h i}$ for productive targets $\left(y_{i} \geq \frac{\tau}{b}\right)$, and $\phi^{l o} \leq \phi_{i, j}<\phi^{h i}$ for less productive targets $\left(y_{i}<\frac{\tau}{b}\right)$ and ii) both firms together have enough resources to pay for their upfront costs, which can be expressed using the feasibility constraint as $y_{i}\left(\phi_{i, j}, y_{j}\right) \geq \underline{y}_{i}$. Based on these conditions, the mass 
of low- and high-value acquisitions are ${ }^{9}$

$$
n^{l o} \equiv \int_{\phi^{l o}}^{\phi^{h i}} \iint_{\min \left(\frac{b}{\tau}, \underline{y}_{i}\right)}^{\frac{b}{\tau}} d G_{i} d G_{j} d F \quad \text { and } \quad n^{h i} \equiv \int_{\phi^{h i}} \iint_{\underline{y}_{i}} d G_{i} d G_{j} d F,
$$

where $F, G_{j}$ and $G_{i}$ denote the distributions of $\phi_{i, j}, y_{j}$ and $y_{i}$. Starting from the innermost integral, the limits of integration refer to the relevant ranges of the gross profits of the target firm, the gross profits of the acquiring firm, and the synergy parameter of the acquisition.

Limiting Case: Unconstrained Acquirer. When an acquirer's profits tend towards infinity, $y_{j} \rightarrow \infty$, he does not face any borrowing constraints (as long as $\tau>0$ ), so that acquisitions are always feasible and take place whenever they generate a positive surplus, i.e. whenever $S \geq 0$. For this set of unconstrained acquirers, denoted by an asterisk, the mass of low- and high-value acquisitions are

$$
n^{l o^{*}} \equiv \int_{\phi^{l o}}^{\phi^{h i}} \int^{\frac{b}{\tau}} d G_{i} d F \quad \text { and } \quad n^{h i^{*}} \equiv \int_{\phi^{h i}} d F
$$

where $F$ and $G_{i}$ denote the distributions of $\phi_{i, j}$ and $y_{i}$. In Figure 1, these sets of acquisitions correspond to the area above $A B C F^{\prime}$.

\subsection{Financial Crises and the Average Acquired Share}

In this section, we ask whether an aggregate financial shock to the economy, modeled as a decrease in $\tau$ from $\tau_{n}$ to $\tau_{c}$, affects the average ownership structures observed in the market for corporate control. We start by defining these average acquired shares. For constrained firms, it is denoted by $\hat{\alpha}$ and can be expressed as the weighted sum of the average shares of low- and high-value acquisitions, $\hat{\alpha}^{l o}=\frac{\alpha^{l o}}{n^{l o}}$ and $\hat{\alpha}^{h i}=\frac{\alpha^{h i}}{n^{h i}}$, with the weights being the share of these two types of acquisitions in the total number of unconstrained acquisitions:

$$
\hat{\alpha}=\omega \hat{\alpha}^{l o}+(1-\omega) \hat{\alpha}^{h i}
$$

\footnotetext{
${ }^{9}$ Note that the joint borrowing constraint can potentially be tighter than the individual borrowing constraint for the target firm. To ensure that the lower limit of the inner-most integral (over the target firm's $y_{i}$ ) is always smaller or equal to the upper limit, we set it equal to $\min \left(\underline{y}_{i}, \frac{b}{\tau}\right)$ for low-value acquisitions.
} 
where $\omega={\frac{n^{l o}}{n^{l o}+n^{h i}}}^{10}$. The equivalent expressions for the average share $\hat{\alpha}^{*}$ acquired by unconstrained firms, i.e. firms with $y_{j} \rightarrow \infty$, is: ${ }^{11}$

$$
\hat{\alpha}^{*}=\omega^{*} \hat{\alpha}^{l o^{*}}+\left(1-\omega^{*}\right) \hat{\alpha}^{h i^{*}} .
$$

Before proceeding further, we make a key assumption about the relationship between ownership structures and the synergies parameter. In particular we assume that the share acquired $\alpha_{i, j}$ is increasing in the synergy parameter $\phi_{i, j}$ associated with the acquirer-target pair $(i, j)$, i.e., $\alpha^{\prime}\left(\phi_{i, j}\right)>0$. We remain agnostic about the reasons for this positive relationship. It could be that firms acquire larger shares of targets in expectation of stronger technological synergies, or that larger acquisition shares lead to strong synergies, or both. Both of these forces would arise in contracting models of joint ventures (Asiedu and Esfahani, 2001) or acquisitions (Alquist et al., 2017). ${ }^{12}$ The assumption is also natural in the context of the emerging markets data that we use later to test the model, where Chari, Ouimet and Tesar (2010) find that acquisitions of majority $(\geq 50 \%)$ stakes are associated with positive abnormal returns of $1.16 \%$, on average. ${ }^{13}$ In addition, Alquist et al. (2017) report a positive correlation in EMEs between the likelihood of full foreign acquisitions and productivity at the level of the target industry. Thus, while both these papers find a discontinuous positive relationship between ownership and productivity $\left(\alpha_{i, j}\right.$ and $\phi_{i, j}$, in our terminology), we assume a continuous positive relationship for analytical simplicity. ${ }^{14}$ Our assump-

${ }^{10}$ The average shares for low- and high-value acquisitions by constrained acquirers are given by:

$$
\hat{\alpha}^{l o}=\frac{\alpha^{l o}}{n^{l o}}=\frac{\int_{\phi^{l o}}^{\phi^{h i}} \iint_{\min \left(\frac{b}{\tau}, \underline{y}_{i}\right)}^{\frac{b}{\tau}} \alpha_{i, j} d G_{i} d G_{j} d F}{\int_{\phi^{l o}}^{\phi^{h i}} \iint_{\min \left(\frac{b}{\tau}, \underline{y}_{i}\right)}^{\frac{b}{\tau}} d G_{i} d G_{j} d F} \quad \text { and } \quad \hat{\alpha}^{h i}=\frac{\alpha^{h i}}{n^{h i}}=\frac{\int_{\phi^{h i}} \iint_{\min \left(\frac{b}{\tau}, \underline{y}_{i}\right)} \alpha_{i, j} d G_{i} d G_{j} d F}{\int_{\phi^{h i}} \iint_{\min \left(\frac{b}{\tau}, \underline{y}_{i}\right)} d G_{i} d G_{j} d F}
$$

${ }^{11}$ In the expression for $\hat{\alpha}^{*}, \omega^{*}=\frac{n^{l o^{*}}}{n^{l 0^{*}}+n^{h i^{*}}}, \hat{\alpha}^{l o^{*}}=\frac{\alpha^{l o^{*}}}{n^{l o^{*}}}$ and $\hat{\alpha}^{h i^{*}}=\frac{\alpha^{h i^{*}}}{n^{h i^{*}}}$. Here, $\alpha^{l o^{*}} \equiv \int_{\phi^{l o}}^{\phi^{h i}} \int^{\frac{b}{\tau}} \alpha_{i, j} d G d F$ and $\alpha^{h i^{*}} \equiv$ $\int_{\phi^{h i}} \alpha d F$ denote the sum of acquired shares in low- and high-value acquisitions. Note that with $y_{j} \rightarrow \infty$, the expressions for these averages do not need to include the integrals over $y_{j}$.

${ }^{12}$ Suppose an acquirer expects exogenously larger value gains from an acquisition. The acquirer will then take a larger equity share in order to retain a higher share of the surplus from the acquisition. In the case that the value gains endogenously arise from the provision of inputs such as intangible capital, management or knowhow, the acquirer might choose a larger stake to commit to providing such inputs optimally. Our model does not analyze these various motives and trade-offs that acquirers and targets face when choosing an optimal degree of ownership. Instead, we want to highlight a different force, in particular, shifts in aggregate financial conditions, that affect the average acquired share observed in the cross-section of acquisitions. Any changes in the average acquired share that we analyze later on will therefore be driven by changes in the composition of the pairs of firms for which an acquisition is successful.

${ }^{13}$ Chari, Ouimet and Tesar (2010) use an event-study methodology in a sample of acquisitions of emerging market (EM) targets by both developed market (DM) and emerging market (EM) acquirers. While gains exist for both DM-EM and EM-EM acquisitions, they are found to be higher for the former. The gains appear to be associated with the transfer of intangible assets from acquiring to target firms, since the effect is larger in weaker contracting environments and for firms in industries with high asset intangibility.

${ }^{14}$ We also tried $\alpha\left(\phi_{i, j}\right)$ with discontinuously higher synergies at ownership shares above $50 \%$ to match the findings of Chari, Ouimet and Tesar (2010), but this does not change our results. We find in our quantitative assessments of the model that 
tion implies that low-value acquisitions $\left(\phi^{l o} \leq \phi_{i, j}<\phi^{h i}\right)$ feature lower acquired shares than high-value acquisitions $\left(\phi_{i, j} \geq \phi^{h i}\right)$.

We now ask how an aggregate financial shock differentially affects the share acquired by constrained firms compared to the share acquired by unconstrained firms. Focusing on the differential lets us capture how financial constraints of the acquiring firms shape the aggregate effect of the shock. Since the shock affects both acquirers and targets in reality, the differencing cancels out the component of the shock that works through the financial constraints of targets alone. ${ }^{15}$ Specifically, we look at the derivative $\frac{\partial\left(\hat{\alpha}-\hat{\alpha}^{*}\right)}{\partial \tau}$, where $\hat{\alpha}$ and $\hat{\alpha}^{*}$ are as defined in equations 2.9 and 2.8, and $\tau$ is the parameter governing aggregate financial conditions. Our later empirical test of the model follows this analysis closely, using a differencein-difference strategy.

To gain insight into the derivative $\frac{\partial\left(\hat{\alpha}-\hat{\alpha}^{*}\right)}{\partial \tau}$, it is useful to decompose the above derivative using the expressions for $\hat{\alpha}$ and $\hat{\alpha}^{*}$ in equations (2.9) and (2.8), as follows:

$$
\begin{aligned}
\frac{\partial\left(\hat{\alpha}-\hat{\alpha}^{*}\right)}{\partial \tau} & =\left[\left(\hat{\alpha}^{h i^{*}}-\hat{\alpha}^{l o^{*}}\right)-\left(\hat{\alpha}^{h i}-\hat{\alpha}^{l o}\right)\right] \frac{\partial \omega}{\partial \tau}+\left(\hat{\alpha}^{h i^{*}}-\hat{\alpha}^{l o^{*}}\right)\left(\frac{\partial \omega^{*}}{\partial \tau}-\frac{\partial \omega}{\partial \tau}\right) \\
& +\left[\omega \frac{\partial \hat{\alpha}^{l o}}{\partial \tau}+(1-\omega) \frac{\partial \hat{\alpha}^{h i}}{\partial \tau}\right]-\left[\omega^{*} \frac{\partial \hat{\alpha}^{l o^{*}}}{\partial \tau}+\left(1-\omega^{*}\right) \frac{\partial \hat{\alpha}^{h i^{*}}}{\partial \tau}\right] .
\end{aligned}
$$

While the magnitudes of some of the individual components depend on specific assumptions regarding the distribution of expected profits, $G$, and the joint borrowing constraint, $B_{i, j}$, the decomposition above is quite general. Hence it is instructive to examine the components in more detail. The first row refers to changes in the share of low-value acquisitions, $\partial \omega / \partial \tau$ and $\partial \omega^{*} / \partial \tau$ (for constrained and unconstrained acquirers respectively), also called the extensive margin. The second row, the intensive margin, refers to the changes in the average acquired share for each subgroup of low- and high-value acquisitions.

The extensive margin differs substantively for constrained and unconstrained acquirers: For unconstrained acquirers, the negative financial shock increases the share $\omega^{*}$ of low-value acquisitions (region $\overline{B C D E}$ in Figure 1) as a larger proportion of potential target firms find themselves unable to raise enough external debt financing to cover the upfront cost of operating in the second period, and thus face liquidation. Coupled with our assumption that $\alpha^{\prime}\left(\phi_{i, j}\right)>0$, this implies a decline in the average share coming from this channel. For constrained acquirers, this effect is counterbalanced by a second effect: A financial shock also tightens the joint borrowing constraint, shifting the $\phi_{i, j}=\underline{\phi}\left(y_{i}, y_{j}, \tau\right)$ line up from $X X^{\prime}$ to $Y Y^{\prime}$ (see Figure 1) and making it harder for firms to acquire targets. This dampens the increase in the

$\alpha_{i, j}=0.5$ corresponds to $\phi_{i, j}$ well above 1 , and at that level of $\phi_{i, j}$, the joint borrowing constraint is almost never binding. Thus a discontinuous increase of $\phi_{i, j}$ at the threshold of $\alpha_{i, j}=0.5$ does not affect our results significantly.

${ }^{15}$ Most of the literature on M\&As has focussed on the implications of financial constraints on the side of the target firm, see for example Erel, Jang and Weisbach (2014), Wang and Wang (2015), Alquist, Mukherjee and Tesar (2016), and Alquist et al. (2017). One exception is Almeida, Campello and Hackbarth (2011), who consider the optimal financial policy of potentially constrained acquiring firms. In contrast, we focus on the aggregate selection effects driven by acquirers' financial positions. 
share of low-value acquisitions because some low-value acquisitions cannot take place as acquirers find themselves unable to raise sufficient funds. Importantly, this shift in the joint-borrowing constraint can, under certain conditions, disproportionately affect low-value acquisitions. Borrowing constraints skew the distribution of acquired firms further towards acquisitions with higher synergies. Some low-synergy acquisitions that might still be profitable, suddenly become infeasible if neither the target nor the acquirer has enough liquidity. This aggregate extensive margin for constrained acquirers depends on the distribution of expected profits in the economy, $G$, as well as the precise form of the joint borrowing constraint, $B_{i, j} \cdot{ }^{16}$

The intensive margin does not react to the aggregate shock in the case of unconstrained acquirers. Since the mass and composition of their high-value acquisitions are unaffected by the financial crisis, the average acquired share within that group does not change, i.e., $\frac{\partial \hat{\alpha}^{h i^{*}}}{\partial \tau}=0$. The crisis leads to an increase in the mass of low-value acquisitions, but this increase is independent of $\phi_{i, j}$, so that the average acquired share of low-value acquisitions remains constant, i.e., $\frac{\partial \hat{\alpha}^{l^{*}}}{\partial \tau}=0$. For constrained acquirers, the sign and magnitude of the intensive margin depends on which firms are affected more by the shift of the borrowing constraint, i.e., on $G$ and $B_{i, j}$.

Hence to pin down the extensive and intensive margins for constrained acquirers, we make further assumptions regarding $G$ and $B_{i, j}$. We assume that $G$ is Pareto, and that $B_{i, j}$ is multiplicative in the expected profits of both acquirer and target. We specify and discuss these assumptions extensively in the appendix. In the following proposition we first analytically prove that under these assumptions the acquired share of constrained firms, relative to that of unconstrained firms, should rise in response to an aggregate tightening of financial constraints.

\section{Proposition 1 Increase in relative acquired shares of constrained firms during crises}

Under Assumptions 1 through 3 (listed in the appendix), the shares acquired by constrained firms relative to the shares acquired by unconstrained firms become larger during financial crises, i.e. if $\tau_{c}<\tau_{n}$ then $\hat{\alpha}_{c}-\hat{\alpha}_{c}^{*}>\hat{\alpha}_{n}-\hat{\alpha}_{n}^{*}$.

Proof: See Technical Appendix.

The proof of the proposition, detailed in the appendix, works by determining the sign and magnitude for

\footnotetext{
${ }^{16}$ Technically, this disproportionate effect on low-value acquisitions requires a positive second derivative of the joint borrowing constraint (2.5) with respect to $\tau$ and $y_{i}$. In Figure 1, this effect is illustrated through a larger rightward shift of the joint borrowing constraint towards higher $y_{i}$ for smaller values of $\phi_{i, j}$. It also depends on $G_{i}$, the distributions of $y_{i}$, in particular its second derivative.
} 
each of the components of equation 2.10 separately:

$$
\begin{aligned}
\frac{\partial\left(\hat{\alpha}-\hat{\alpha}^{*}\right)}{\partial \tau} & =\left[\left(\hat{\alpha}^{h i^{*}}-\hat{\alpha}^{l o^{*}}\right)-\left(\hat{\alpha}^{h i}-\hat{\alpha}^{l o}\right)\right] \underbrace{\frac{\partial \omega}{\partial \tau}}_{=0}+\underbrace{\left(\hat{\alpha}^{h i^{*}}-\hat{\alpha}^{l o^{*}}\right)}_{>0} \underbrace{\left(\frac{\partial \omega^{*}}{\partial \tau}-\frac{\partial \omega}{\partial \tau}\right)}_{<0} \\
& +\underbrace{\left[\omega \frac{\partial \hat{\alpha}^{l o}}{\partial \tau}+(1-\omega) \frac{\partial \hat{\alpha}^{h i}}{\partial \tau}\right]}_{=0}-\underbrace{\left[\omega^{*} \frac{\partial \hat{\alpha}^{l o^{*}}}{\partial \tau}+\left(1-\omega^{*}\right) \frac{\partial \hat{\alpha}^{h i^{*}}}{\partial \tau}\right]}_{=0}<0 .
\end{aligned}
$$

First, for unconstrained acquirers, as explained earlier, the extensive margin lowers the average share acquired, while the intensive margin does not react to a change in $\tau$. This happens irrespective of distributional assumptions. Second, for constrained acquirers, for Pareto-distributed $G$, the magnitude of the two counteracting extensive margin effects described earlier - the increase in the potential pool of low-value acquisitions and the decrease in the feasibility to complete low-value acquisitions - perfectly cancel each other out, so that the share of low-value acquisitions, $\omega$, remains unaffected by the change in the constraint parameter $\tau$. Hence the extensive margin change is absent in this special case. At the same time, the intensive margin for constrained acquirers does not move, due again to the Pareto distribution assumption: Even though the lowest-value acquisitions are hit hardest among low-value acquisitions by the shift of the borrowing constraint, their relative mass does not go down, keeping the average acquired share of low-value acquisitions constant. Thus under our particular assumptions, the decrease in the average acquired share comes purely from a change in the composition of acquisitions (extensive margin) for unconstrained acquirers rather than any changes in the average acquired share of low-value acquisitions and high-value acquisitions (intensive margin).

As we emphasized, whether the share acquired by constrained firms remains exactly constant eventually depends on the firm profit distribution $G$ and the joint-borrowing constraint $B_{i, j}$. The key of this section was to provide intuition about the two counteracting forces that determine the observable average ownership structure chosen for constrained acquirers, and to delineate the assumptions under which we can assign an unambiguous sign to their net effect. In a later section we simulate the model numerically and find that under certain plausible conditions, the decrease in the feasibility to complete low-value acquisitions actually dominates the increase in the low-value target pool, and as a result, the average share by constrained acquiring firms even goes up in the aftermath of an aggregate financial shock. Thus, we will use the decomposition provided by equation (2.10) and Proposition 1 as a simple benchmark case to guide and interpret our empirical implementation later. 


\subsection{Three-Period Model Setup}

The analysis so far has been static. To study the effect of a financial shock on the dynamics of ownership, we now allow for the possible resale of firms after an acquisition. We show that the selection effects based on technological synergies and liquidity that influenced average ownership structures might also influence post-acquisition ownership dynamics. In particular, we show that in the presence of asset sales driven by idiosyncratic liquidity shocks to the owner of the asset, an aggregate financial shock leads to the selection of liquid acquirers into the market for corporate control, thereby lowering asset ownership turnover. In this section we briefly outline the steps used to solve the dynamic (three-period) version of the model and provide intuition behind the main results. Detailed statements and proofs of the underlying propositions are relegated to the appendix.

We extend the model in the previous section by an additional period, period 2. When we later analyze the effects of financial crises on divestiture rates, we model period 1 as a crisis period with tighter borrowing constraints and period 2 as a "normal" period, where financial conditions have returned to their previous state. In period 1, after profits for that period have been realized, the acquirer $j$ receives an all-or-nothing offer for her entire share of the firm that was purchased in period 0 . We make two main assumptions to simplify the analysis substantially: (i) every prospective seller in period 1 can find a new acquirer to buy back his initial period 0 acquisition, and similarly, every target firm that was not acquired in period 0 can find a new acquirer in period 1; and (ii) the new acquirer making the buy-back offer operates the firm using the same technology as the original owner of the firm (i.e. $\phi_{i, j}=1$ ). These two assumptions together allow for a simple diagrammatic analysis of the resale decision. ${ }^{17}$ In the static model, acquisitions occurred simply on the basis of profitability and feasibility. However, since resale of the asset involves comparing the payoff from the resale to the payoff from retaining ownership of the asset, we need additional assumptions on the division of the surplus from an acquisition as well as the stochastic process of profitability in periods 1 and 2. These latter assumptions - Nash bargaining between acquirers and targets over surplus and an autoregressive process for profits - are relatively standard and are discussed in the appendix.

While the exposition and analysis of asset resales can be found in the appendix, we briefly discuss our main results and the intuition behind them in the following paragraphs. In period 1, it is optimal

\footnotetext{
${ }^{17}$ The assumption that every target firm that was not acquired in period 0 can find a new acquirer implies that the outside options for target firm and acquirer at the end of period 1 are the same and therefore do not affect the surplus of the initial acquisition. This assumption together with the assumption that the new acquirer has $\phi_{i, j}=1$ keeps the relevant acquisition cutoffs $\phi^{l o}$ and $\phi^{h i}$ the same as in the static model. One can relax the assumption that sellers find a buyer with certainty. Reducing this probability is similar to introducing a discount factor. This being said, it is true that these assumptions are less innocuous if we believe that parameters are changing over the business cycle. For example, the probability of finding a buyer or the potential outside offer can change over the business cycle. These extensions might give use additional insights on flipping behavior, but we believe that they are orthogonal to the mechanism discussed in this section. Note that we no longer require the assumption that the acquired share $\alpha$ positively depends on the synergy parameter $\phi_{i, j}$.
} 
for the initial acquirer $j$ to resell the firm $i$ whenever the value of reselling exceeds the value of holding onto the firm. The resale value depends on the expected net profits from production in period 2 for the new acquirer who makes the offer to buy. The value of holding onto the firm depends on the expected liquidity position of the post-acquisition entity (i.e. the acquirer-target entity resulting from the period 0 acquisition), since this entity will become financially constrained at the end of period 1 with some probability, and thus be unable to produce.

Resales then happen under two circumstances. First, all initial acquisitions that were driven by pure liquidity provision (low-value acquisitions) get resold because the target firm no longer requires liquidity for production in period 2. For ease of exposition we call these "normal flips". Under our assumptions, this is the case for $\phi_{i, j}<\phi^{h i}=1$. This type of flipping occurs even if the post-acquisition entity is liquid enough to produce in period 2. Second, even some high-synergy acquisitions with $\phi_{i, j} \geq \phi^{h i}=1$ might get flipped. This happens whenever the post-acquisition entity becomes liquidity-constrained at the end of period 1. We refer to this type of flipping as "forced flipping". The probability of forced flipping coincides with the probability of the post-acquisition entity not having enough liquidity, conditional on having had enough liquidity in the first period. Since unconstrained acquirers have enough liquidity by definition, forced flipping is only relevant for constrained acquirers.

We can now combine the period 1 resale decision with the initial period 0 acquisition decision-the details of which are in the appendix-to obtain five cases, illustrated in Figure 4. No acquisition takes place in cases 1 and 3 because synergies are too low. In case 1, the target firm exits the market because it lacks liquidity to pay for the upfront cost of production; in case 3, the target firm has enough liquidity to produce by itself, but the synergies are too low to justify an acquisition. These two cases coincide perfectly with the corresponding cases ("exit the market" and "not acquired/potental acquirer") in Figure 1. This is a consequence of the simplifying assumptions (i) and (ii) noted at the beginning of this section. Case 2 gives rise to low-value acquisitions that will be flipped at the end of period 1 with certainty, as discussed above. Finally, cases 4 and 5 comprise combinations of $\phi_{i, j}$ and $y_{i, 1}$, where initial acquisitions take place, but those high-value acquisitions might be flipped at the end of period 1 if the acquirer is constrained and realizations of second-period profits are low.

\subsection{Financial Crises and Asset Resales}

We now ask how financial crises affect asset resales among acquisitions. We compare flipping rates for acquisitions at the end of period 1 under two scenarios. In scenario 1 , all periods are normal periods with $\tau_{1}=\tau_{2}=\tau_{n}$. In scenario 2 , the financial crisis occurs at the end of period 0 , but is over by the end of period 1, i.e. $\tau_{1}=\tau_{c}<\tau_{2}=\tau_{n}$. Flipping, or divestiture, rates are defined as the number of acquisitions flipped at the end of period $1, n^{\text {flip }}$ over the number of total acquisitions made at the end of period $0, n$.

From our discussion above (and as proved in the appendix), unconstrained acquirers only flip low- 


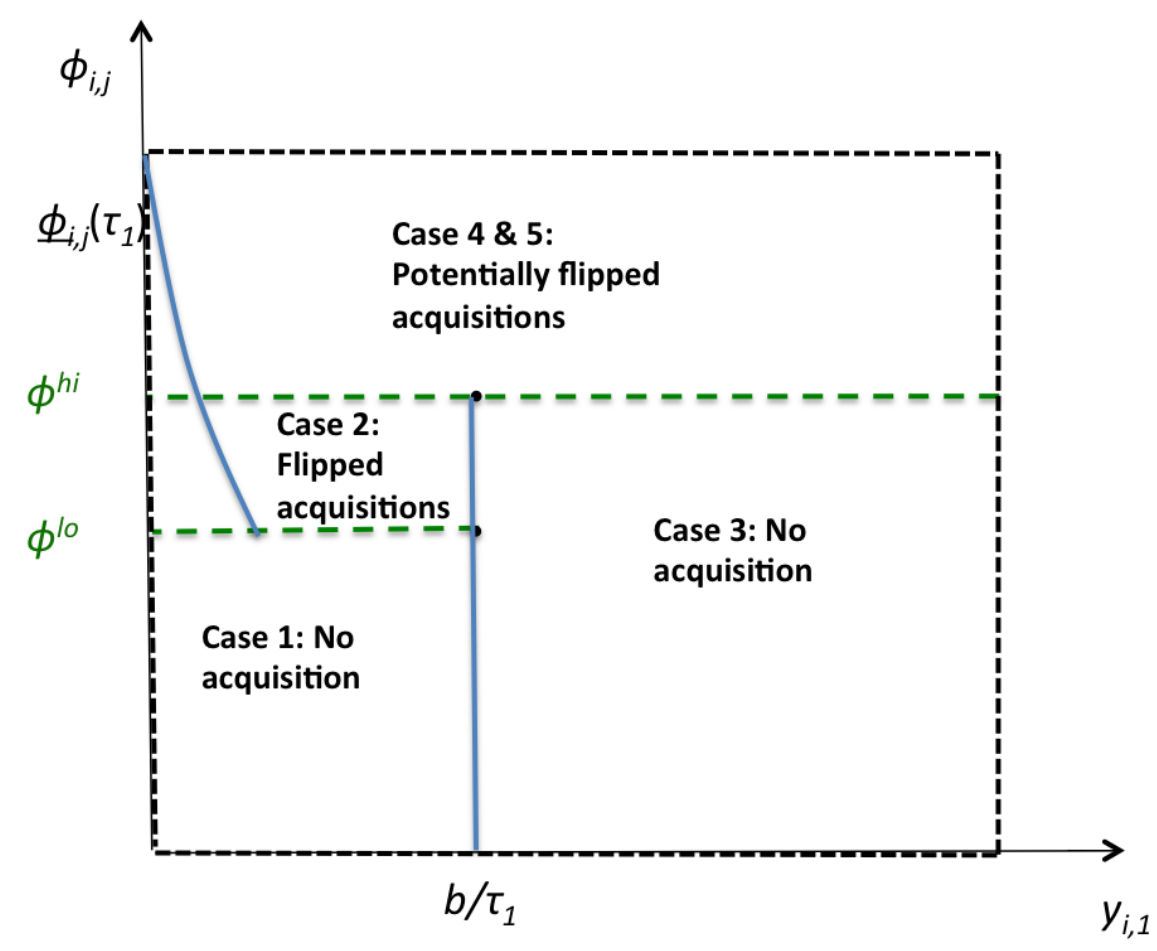

Figure 2: Resale of Acquired Firms

Notes: Figure displays combinations of the synergy parameter $\phi_{i, j}$ and the expected profits $y_{i, 1}$ of a target firm, which can be initially acquired and then resold ('flipping'). The joint borrowing constraint $\underline{\phi}_{i, j}$ is drawn for a constrained acquirer with a given liquidity level $y_{j, 1}$. For cases 2 and 4 , only firms with $\phi_{i, j} \geq \underline{\phi}_{i, j}$ are acquired. See text and appendix for further details on the different cases.

value acquisitions (normal flips), so that their flipping rate is simply

$$
\frac{n^{f l i p^{*}}}{n^{*}}=\frac{n^{l o^{*}}}{n^{l o^{*}}+n^{h i^{*}}}=\underbrace{\omega^{*}}_{\text {normal }}
$$

where $\omega^{*}$ is the share of low-value acquisitions. In contrast to unconstrained firms, constrained acquirers might, in addition, be forced to flip some of their high-value acquisitions:

$$
\frac{n^{f l i p}}{n}=\frac{n^{l o}+(1-p) n^{h i}}{n^{l o}+n^{h i}}=\frac{n^{l o}}{n^{l o}+n^{h i}}+\frac{(1-p) n^{h i}}{n^{l o}+n^{h i}}=\underbrace{\omega}_{\text {normal }}+\underbrace{(1-p)(1-\omega)}_{\text {forced }},
$$

where $\omega$ is the share of low-value acquisitions and $p$ is the share of high-value post-acquisition entities that have enough liquidity at the end of period 1 (out of the total mass of high-value post-acquisition 
entities). The mass of asset resales for constrained acquirers is thus made up of a mass $\omega$ of "normal" flips and a mass $(1-p)(1-\omega)$ of "forced" flips.

We now ask how an aggregate financial shock differentially affects the flipping rates of acquisitions made by constrained firms compared to those by unconstrained firms. As with the acquired share, focussing on the differential effect lets us capture any change in divestiture rates that work through the financial constraints of the acquiring firm alone.

\section{Proposition 2 Decrease in relative flipping rates for acquisitions made by constrained acquirers during crises}

Under Assumptions 2 through 4 (listed in the appendix), flipping rates of acquisitions made by constrained firms relative to those made by unconstrained firms become smaller for acquisitions made during financial crises, i.e. if $\tau_{c}<\tau_{n}$ then $\frac{n_{c}^{f l i p}}{n_{c}}-\frac{n_{c}^{f l i p^{*}}}{n_{c}^{*}}<\frac{n_{n}^{f l i p}}{n_{n}}-\frac{n_{n}^{f l i p^{*}}}{n_{n}^{*}}$.

To understand the intuition behind this result, it is instructive to look at the derivative, with respect to $\tau_{1}$, of the differential flipping rate:

$$
\frac{\partial\left(\frac{n^{f l i p}}{n}-\frac{n^{f l i p^{*}}}{n^{*}}\right)}{\partial \tau_{1}}=\underbrace{\frac{\partial \omega}{\partial \tau_{1}}}_{=0}+\underbrace{\frac{\partial}{\partial \tau_{1}}(1-p)(1-\omega)}_{>0}-\underbrace{\frac{\partial \omega^{*}}{\partial \tau_{1}}}_{<0}>0 .
$$

We examine each of the terms on the right hand side of the expression above in turn. The last term is the response of the divestiture rate of unconstrained firms to a negative financial shock in the economy. Since unconstrained firms only flip low-value acquisitions, the change in the proportion of flipped unconstrained acquisitions is simply equal to the change in the share of low-value acquisitions in all acquisitions by unconstrained acquirers. This, as shown earlier, increases (i.e. $\frac{\partial \omega^{*}}{\partial \tau_{1}}<0$ ) when there is an adverse aggregate financial shock (i.e. decline in $\tau_{1}$ ) due to more potential target firms requiring liquidity.

The first two terms show the response of constrained firms and suggest two differences relative to the case with unconstrained acquirers: The first term shows the changes in the share of low-value acquisitions that get flipped. A main insight from Proposition 1 in Section 2.2 was that this share of low-value acquisitions does not change for constrained acquirers during crises due to two counterbalancing effects. This keeps flipping rates low. Here it should be noted that there being no change in "normal" flipping rates for constrained acquirers is a knife-edge result that rests on the distributional assumptions we made. Hence in the next section we will attempt an empirical assessment of the size of this effect.

The second term refers to changes in the number of "forced" resales caused by acquirers running into liquidity problems. As emphasized in Section 2.2, only firms with large expected profits can raise sufficient funds to undertake acquisitions during financial crises. To the extent that firms' expected profits are somewhat persistent, it is less likely that these firms will face liquidity problems in the aftermath of 
the financial crisis, which will reduce the flipping rates for acquisitions made by constrained acquirers during financial crises. ${ }^{18}$

The lower flipping rates observed for crisis-cohort acquisitions are therefore the result of a double "selection effect" stemming from the acquirer's side: Only the highest-synergy acquisitions (i.e. large $\phi_{i, j}$ ) take place, and only the most-liquid firms (i.e. large $y_{j, 1}$ ) acquire targets. In the following empirical section, we directly test Proposition 2 using a difference-in-difference approach. In addition, since the proposition holds only under particular distributional assumptions, we also attempt to empirically determine the signs and magnitudes of the three terms discussed above.

\section{Model Versus Data}

In this section we compare the predictions of the model with the data as follows. We first describe the data that we use to calibrate the model and perform the model-data comparisons in Section 3.1. We then simulate the model in Section 3.2 to obtain the shares acquired by constrained and unconstrained firms under normal and crisis periods. We do so under different parameter values, some of which are calibrated to the data. We then describe and motivate our difference-in-difference empirical framework and use it to analyze this simulated data, as well as its empirical counterpart, in Section 3.3. This enables a direct comparison of the model with the data, as well as the estimation of certain empirical marginal effects that we deliberately leave out of the model to simplify and focus the analysis.

\subsection{Data Description}

As discussed earlier, most of the literature on M\&As in emerging market and transition economies focusses on the financial constraints of target firms and how acquisitions relieve these constraints. In contrast, our paper analyzes the consequences of acquirers' financial constraints. This leads us to focus on emerging markets M\&As, where general financial underdevelopment is likely to constrain local acquirers as well as targets. We take the model to the data using transaction level data for domestic and crossborder M\&As from the Thompson-Reuters Securities Data Company Platinum database. SDC contains information on the universe of such deals in a large set of EMEs. ${ }^{19}$ For each transaction, we utilize a few key variables - the share of a firm acquired in an acquisition and owned after an acquisition, the names of the firms involved, both their primary two-digit SIC industry classifications, the country of the acquirer

\footnotetext{
${ }^{18}$ More formally, $\partial p /\left.\partial \tau_{1}\right|_{\tau_{2}}<0$ : Given a borrowing constraint level in the second period, $\tau_{2}$, a tighter borrowing constraint in the first period $\left(\tau_{1} \downarrow\right)$ raises the probability that the post-acquisition entity has enough liquidity at the end of the second period, $p$. Importantly, it is the increase of $\tau$ from a low crisis value $\tau_{1}=\tau_{c}$ to a high value $\tau_{2}=\tau_{n}$ that raises this probability $p$.

${ }^{19} \mathrm{We}$ only include the target countries that have significant activity in the M\&A market, namely Argentina, Brazil, Chile, China, India, Indonesia, Malaysia, Mexico, Peru, Philippines, Singapore, South Africa, South Korea, Taiwan, Thailand, and Vietnam. The fewest number of acquisitions (109 over the eighteen year sample period) took place in Vietnam.
} 
and target firm, and the date on which the transaction was completed - for sixteen of the largest markets for corporate control in EMEs between 1990 and 2007. In all our empirical estimations, we use the sample of acquisitions in which $10 \%$ or more of a firm is acquired. This is done to keep our results comparable to the literature on FDI, since, as explained below we use foreign acquisitions as a comparison group. This leaves us with a sample of 28,109 transactions.

We think of the pool of unconstrained acquiring firms as being based in a country that is financially developed or that has not faced an aggregate negative financial shock. For the purpose of the calibration in the next section, we identify unconstrained acquiring firms with foreign firms and constrained acquiring firms with domestic acquirers. This seems a reasonable assumption because the majority of foreign acquiring firms in our sample were from countries with more well-developed financial markets, not other EMEs. ${ }^{20}$ Similarly, we exclude the post-2007 period since the Great Recession because we believe that foreign firms from developed countries might have been financially constrained during that time period.

\subsection{Calibrating and Simulating the Model}

This section describes the calibration of the model in Section 3.2.1, and the simulation results for acquired shares (Section 3.2.2) and flipping rates (Section 3.2.3).

\subsubsection{Calibration}

We simulate the model to analyze the reaction of the average acquired share and flipping rates to a tightening of the borrowing constraint. We first have to choose functional forms and parameters. Some of these parameters are chosen to match certain features of the data on emerging market acquisitions described above.

We first normalize the fixed cost / debt parameter $b$ to 1 . The borrowing constraint parameter, $\tau$, corresponds to the maximum debt-to-value in our model. We choose $\tau=0.75$ during normal times and $\tau=0.6$, translating into a 25 percent decline in the maximum debt-to-value ratio. In the analytical section, we had assumed a joint borrowing constraint where the two firms' expected profits are neither substitutes nor complements. This was partly done for analytical convenience. In our simulation, we show that our results from the analytical section are robust to an alternative, and perhaps more natural, assumption that banks consider acquirer's and target's expected profits as perfect substitutes:

$$
2 b \leq \tau\left(\phi_{i, j} y_{i}+y_{j}\right) .
$$

\footnotetext{
${ }^{20}$ This is documented in Alquist et al. (2017) using indices of financial development such as private credit/GDP and bond market capitalization/GDP ratios. More generally, unconstrained firms can also be large domestic firms in EMEs that face only very loose financing constraints. However there does not exist firm-level data on size or financial constraints for most of the EME firms in our sample, hence we rely on developed market firms as the comparison group.
} 
Under this formulation banks consider only the value of the joint acquirer-target entity when extending loans. It would be quite easy to extend the analysis using CES-type functional forms to allow for different degrees of substitutability between acquirer's and target's collateral.

For the distribution of expected profits, $y_{i}$, we choose a log-normal distribution. ${ }^{21}$ Several studies have found that both log-normal and Pareto distributions capture reasonably well the distribution of sales and employment. For example, Di Giovanni, Levchenko and Ranciere (2011) estimate that a Pareto distribution with a shape parameter close to, but above 1 captures the size distribution of firms across many countries. The distribution of sales is closely linked to the distribution of productivity and profits. For instance, in a model with monopolistic competition (see Melitz, 2003, for example), the shape parameter for the sales distribution is simply the elasticity of substitution between the products of firms less the shape parameter of the productivity distribution. Assuming an elasticity of substitution around 6, a shape parameter for the productivity of 5 is consistent with the evidence on the size distribution. We use a log-normal distribution for productivity instead of a Pareto distribution and choose its parameters to match the mean and the variance of a Pareto distribution with scale parameter 1 and shape parameter $5 .^{22}$

We have less guidance on the distribution of synergies, $\phi_{i, j}$, which captures the technological benefits from an acquisition net of the costs of acquisitions (such as those stemming from restructuring, legal fees etc.). We assume a normal distribution with mean 1, which means that half the firm pairs draw synergy parameters that lower the net productivity of the target firm. There is a considerable body of literature in finance that documents value-destruction in M\&As (see for example Moeller, Schlingemann and Stulz, 2005), as well as value gains for shareholder of both acquiring and target firms (Bris and Cabolis, 2008; Chari, Ouimet and Tesar, 2010). Our assumption of a normal distribution takes both these cases into account.

We assume that the acquired share is a function of the synergy parameter:

$$
\alpha_{i, j}=\max \left(0, \min \left(1, \psi_{0} \phi_{i, j}^{\psi_{1}}\right)\right), \quad \psi_{0}>0, \psi_{1}>0
$$

The form for the acquired share function ensures that the acquired share is between 0 and 1 and increasing in $\phi_{i, j}$. Recall that we provided an extensive discussion about the assumption of a continuous and positive relationship between $\alpha_{i, j}$ and $\phi_{i, j}$ in Section 2.2. The parameters $\psi_{0}, \psi_{1}$ and the standard deviation of the distribution of $\phi_{i, j}$ together affect the distribution of acquired shares. As the elasticity $\psi_{1}$ increases, the acquired share is more sensitive to synergies $\phi_{i, j}$, so that small variations in $\phi_{i, j}$ lead to strong variations

\footnotetext{
${ }^{21}$ Note that for domestic acquisitions, $y_{j}$ has the same distribution as $y_{i}$ and for foreign acquisitions the distribution of $y_{j}$ is irrelevant.

${ }^{22}$ We choose the log-normal distribution because we assume that $\log (y)$ follows an $\operatorname{AR}(1)$ process. If the errors of this $\operatorname{AR}(1)$ process are Gaussian, then $\log \left(y_{t}\right)$ is normally distributed as $t \rightarrow \infty$. Our simulations based on a Pareto distributions are almost identical.
} 
Table 1: Acquired Share in Data and Model

\begin{tabular}{lcccccccc}
\hline \hline & $<50$ & $50-60$ & $60-70$ & $70-80$ & $80-90$ & $90-100$ & 100 & $\hat{\alpha}$ \\
\hline Data & $28.8 \%$ & $8.8 \%$ & $5.9 \%$ & $2.5 \%$ & $3.7 \%$ & $2.7 \%$ & $47.7 \%$ & $70.2 \%$ \\
Model & $29.7 \%$ & $5.6 \%$ & $5.1 \%$ & $4.5 \%$ & $4.1 \%$ & $3.8 \%$ & $47.5 \%$ & $72.4 \%$ \\
\hline \hline
\end{tabular}

Notes: The table reports average acquired shares for the total of acquisitions during normal times in the data and the model for different deciles (expressed in percent). For this table, we set $\tau=0.75$.

in $\alpha_{i, j}$. Since we have to restrict $\alpha_{i, j}$ to be between 0 and 1 , an increase in $\psi_{1}$ raises the share of full acquisitions. The parameter $\psi_{0}$ strongly affects the number of acquisitions below $50 \%$. A higher value for $\psi_{0}$ lowers the share of acquisitions below 50\%. Finally, the standard deviation of $\phi_{i, j}$ determines the shape of the acquired share distribution. As it increases, acquired shares $\alpha_{i, j}$ are more and more uniformly distributed.

We choose $\psi_{0}$ and $\psi_{1}$ and the standard deviation of the synergy distribution to match as best as possible the fraction of acquisition below 50\%, the fraction of full acquisitions, and the average acquired share that we observe in the data. Table 1 compares acquired shares in the data and the model. We cannot perfectly match the three moments: Whereas the fraction of acquisition below $50 \%$ is almost identical in model and data, the fraction of full acquisitions is somewhat larger in the data compared to the model, although the average acquired share is smaller. The reason for the discrepancy is that the model does not feature many small scale acquisitions with shares of less than $30 \%$, which can be observed in the data. However, the fit is fairly good for our very parsimonious model. ${ }^{23}$

\subsubsection{Simulated Average Acquired Shares}

Figure 3(a) shows how the average acquired share of both unconstrained and constrained acquirers adjusts to a steady decline of the maximum debt-to-value ratio, $\tau$, in our 2-period model from Section 2.2. During normal times the average acquired share is somewhat higher among constrained firms (0.76 vs. 0.68). As credit constraints tighten, we observe that this gap widens by almost 7 percentage points, in line with Proposition 1 . This widening is driven both by a decrease of the average acquired share for unconstrained acquisitions (by 4 percentage points) and an increase for constrained acquirers (by almost 3 percentage points). Recall that under the specific assumptions underlying Proposition 1, the average acquired share for constrained acquirers stays constant instead of going up. Its precise movement particularly depends on the range of $\tau$ and the form of the joint borrowing constraint, and even though the share might even go down for constrained acquirers, we never found a combination of parameters for which it went down

\footnotetext{
${ }^{23}$ The corresponding parameter values are $\psi_{0}=0.18, \psi_{1}=1.75$ and a standard deviation of 2.5 .
} 
more than it did for unconstrained acquirers.

Figure $3(\mathrm{~b})$ decomposes this overall change in the difference of the average acquired shares across acquirers into three components (where a prime ' denotes the value after the change)

$$
\begin{aligned}
\Delta \hat{\alpha}-\Delta \hat{\alpha}^{*} & =\underbrace{\left(\hat{\alpha}^{l o}-\hat{\alpha}^{h i}\right) \Delta \omega-\left(\hat{\alpha}^{l o^{*}}-\hat{\alpha}^{h i^{*}}\right) \Delta \omega^{*}}_{E x t} \\
& +\underbrace{\omega^{\prime} \Delta \hat{\alpha}^{l o}+\left(1-\omega^{\prime}\right) \Delta \hat{\alpha}^{h i}-\left(\omega^{*^{\prime}} \Delta \hat{\alpha}^{l o^{*}}+\left(1-\omega^{*^{\prime}}\right) \Delta \hat{\alpha}^{h i^{*}}\right)}_{\text {Int }}
\end{aligned}
$$

This decomposition follows equation (2.10). The extensive margin captures the composition effect of a change in the average productivity of low- and high-value acquisitions. The intensive margin refers to changes in the average productivity of the two types of acquisitions. Figure 3(b) shows the result of this decomposition for a change in $\tau$ from 0.75 to 0.6 , both for the net effect (constrained less unconstrained), and for unconstrained and constrained acquirers individually. The net increase in the gap of $7 \%$ stems to two thirds from the extensive margin. This strong extensive margin is mainly driven by unconstrained acquirers. For acquisitions undertaken by constrained acquirers, this composition effect actually flips. Most of the increase in the average acquired share stems for an increase within each type of acquisitions.

\subsubsection{Simulated Flipping Rates}

An additional parameter of our three-period model, that we did not need in the two-period calibration discussed in Section 3.2.1, is the persistence of the temporary productivity, $\rho$. There is little guidance in the literature on this parameter, but it is probably uncontroversial to assume some persistence. We set $\rho=0.5$, which, if we think of one period in our model corresponding to roughly four years, is in line with an annual persistence of about 0.85 . Note that our results remain robust even for $\rho=0$.

Figure 4 displays flipping rates for both constrained and unconstrained acquirers as a function of the borrowing constraint parameter in the crisis, $\tau_{1}$. After the crisis, $\tau$ returns to its normal value of $\tau_{2}=0.75$. For the chosen parameters, flipping rates increase for unconstrained acquirers by 6 percentage points from 11.5 to 17.2 percent, but decrease for constrained acquirers from 18.5 to 16.3 percent. 


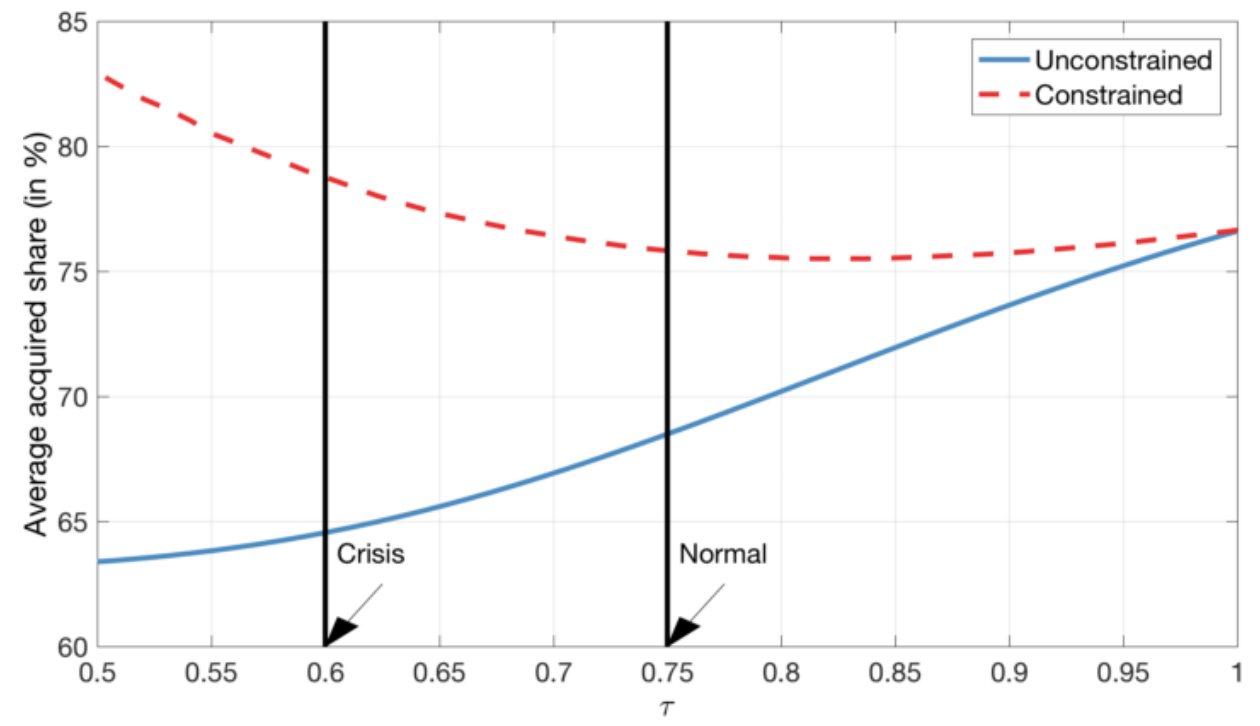

(a) Average Acquired Share
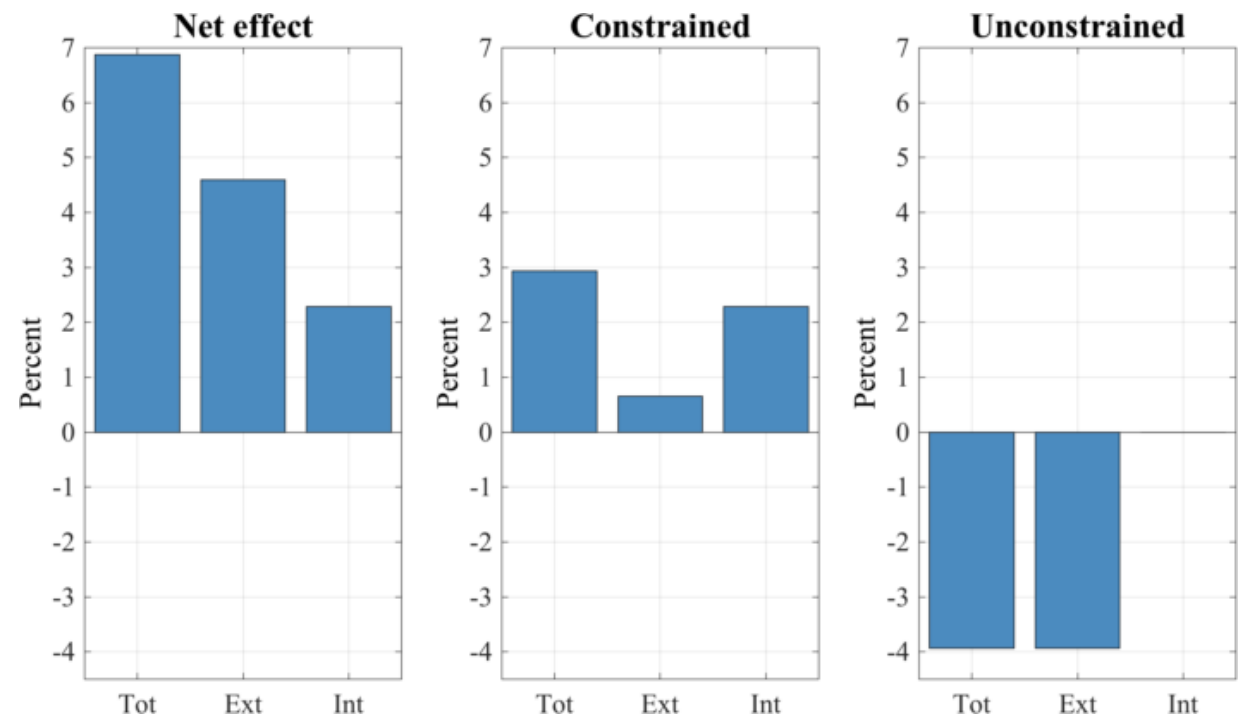

(b) Decomposition of a Change in the Average Acquired Share

Figure 3: Average Acquired Share

Note: Figure (a) shows the simulated average acquired share of firms acquired by unconstrained and constrained firms as a function of the borrowing constraint parameter $\tau$. A financial crisis is modeled as a decrease of $\tau$. Figure (b) decomposes the percentage change from $\tau=0.75$ to $\tau=0.6$ into a composition change, the extensive margin, and a change in the average acquired share of both low-value acquisitions and technology acquisitions (see Equation (3.2)) 


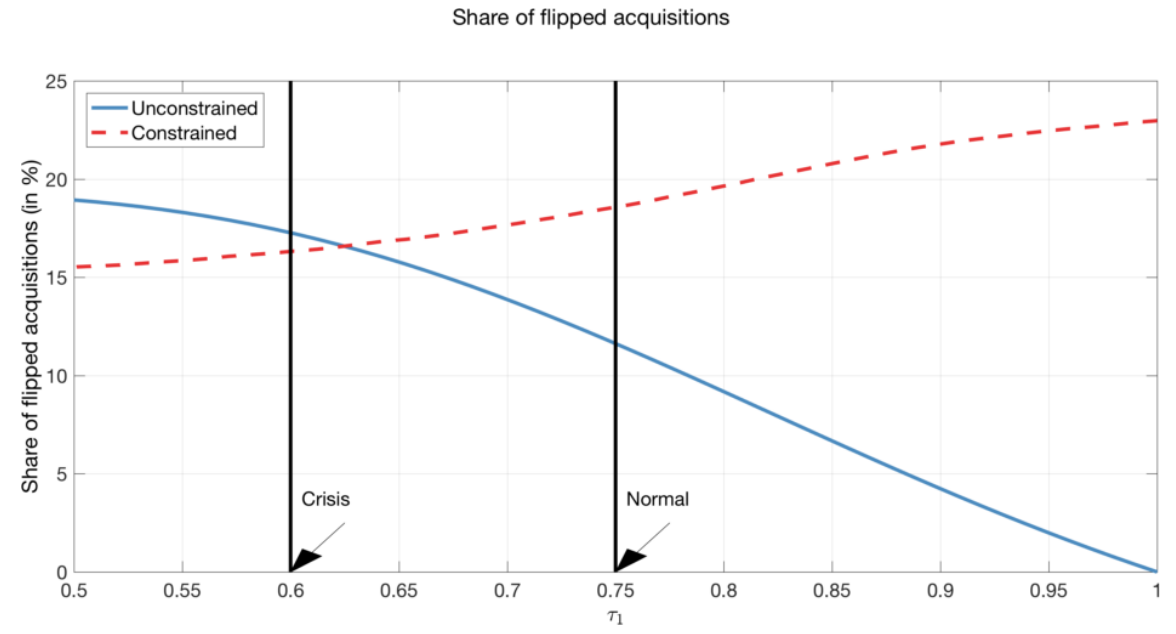

Figure 4: Share of Flipped Acquisitions

Note: Simulated share of flipped acquisitions as a function of financial constraint in the first period, $\tau_{1}$, for unconstrained acquirers (left panel) and constrained acquirers (right panel). The borrowing constraint during normal times is $\tau_{2}=\frac{2}{3}$. For more details, see notes to Figure 3.

\subsection{Regression Analysis of Average Acquired Share and Flipping Rates}

To provide empirical evidence on the acquirer financial constraint channel, we now adopt the same difference-in-difference (DID) strategy that formed the basis of Propositions 1 and 2 in the model section.

\subsubsection{Average Acquired Share: Empirical Strategy, Hypotheses and Results}

Following Proposition 1 we first estimate the magnitude of the differential effect of the crisis on ownership shares acquired by domestic and foreign acquiring firms. For easy interpretability of the coefficients we use a simple OLS specification as our baseline specification. Results using a Generalized Linear Model (to take into account the bounded nature of our dependent variables) are similar and can be found in the appendix. We first estimate the parameters of the following equation to find the overall or total effect of the crisis on ownership shares:

$$
\text { fracacq }_{k j c t}=\beta_{0}^{T o t .}+\beta_{C}^{T o t} \cdot D_{C}^{c t}+\beta_{F}^{T o t .} D_{F}^{k j c t}+\beta_{C, F}^{T o t} D_{C}^{c t} \times D_{F}^{k j c t}+\operatorname{con}^{\prime} \boldsymbol{\beta}_{\boldsymbol{c o n}}+\epsilon_{k j c t} .
$$

The dependent variable in this regression, $f r a c a c q_{k j c t}$, is the fraction of the target firm acquired in a transaction ("fraction acquired"). The subscripts $k, j, c$, and $t$ stand for transaction, single-digit SIC industry of the target firm, target country, and time, respectively. The two main independent variables are $D_{C}^{c t}$, 
which indicates whether an acquisition took place during a period when there was an aggregate adverse financial shock in the target country ("Crisis"), and $D_{F}^{k j c t}$, which indicates whether the acquirer involved in a particular transaction is from a developed market ("Foreign"), which proxies for unconstrained acquirers in our theoretical model. Our crisis dummy $D_{C}^{c t}$ is defined using the (annual) systemic banking crises dates from Laeven and Valencia (2010). The vector con of independent variables used as controls includes fixed effects (at the country $\times$ target-industry level in our baseline specifications) and a set of lagged country-level macroeconomic variables, varying at the country $\times$ year level. The motivation behind these control variables are discussed at length later. Briefly, the fixed effects control for time invariant factors at the country $\times$ target-industry level (for example, that particular industries in particular countries might have unique ownership structures due to regulations), while the macroeconomic variables correct for normal business cycle variation in M\&A activity. Since our main explanatory variables are binary, the baseline group in the above regression, as well as all subsequent ones, is identified by setting $D_{C}^{c t}=0$ and $D_{F}^{k j c t}=0$, simultaneously, which is the subset of domestic acquisitions during normal times.

Next, we decompose the total effect into an extensive and an intensive margin, as in the theoretical model. For identifying the extensive margin empirically, we estimate the following regression:

$$
D_{\text {maj. }}^{k j c t}=\beta_{0}^{E x t .}+\beta_{C}^{E x t .} D_{C}^{c t}+\beta_{F}^{E x t .} D_{F}^{k j c t}+\beta_{C, F}^{E x t} D_{C}^{c t} \times D_{F}^{k j c t}+\operatorname{con}^{\prime} \boldsymbol{\beta}_{\text {con }}+\epsilon_{k j c t},
$$

where the dependent variable is a dummy $D_{\text {maj. }}^{k j c t}$ that takes a value of 1 above some threshold of ownership ("majority"). Recall that the extensive margin in the model (see Proposition 1) refers to changes in the shares of low-value acquisitions $\left(\partial \omega / \partial \tau\right.$ and $\partial \omega^{*} / \partial \tau$ for constrained and unconstrained acquirers, respectively). Furthermore, we argued earlier - based on the empirical findings of Chari, Ouimet and Tesar (2010) and Alquist et al. (2017) - that changes in $\omega$ and $\omega^{*}$ should translate into changes in average ownership structures. Thus the empirical counterpart of extensive margin changes in ownership structure is a compositional shift towards majority (Chari, Ouimet and Tesar, 2010) or full acquisitions (Alquist et al., 2017). In our baseline estimations, we set the threshold of ownership beyond which acquisitions are high-value in EMEs to be 50\% based on Chari, Ouimet and Tesar (2010).

To estimate the intensive margin, we use a specification identical to equation 3.3 in all respects, except that we include a dummy independent variable identifying a majority acquisition:

$$
\operatorname{fracacq}_{k j c t}=\beta_{0}^{\text {Int. }}+\beta_{C}^{\text {Int. }} D_{C}^{c t}+\beta_{F}^{I n t} \cdot D_{F}^{k j c t}+\beta_{C, F}^{I n t} D_{C}^{c t} \times D_{F}^{k j c t}+\beta_{m a j .} D_{m a j .}^{k j c t}+\boldsymbol{c o n}^{\prime} \boldsymbol{\beta}_{\boldsymbol{c o n}}+\epsilon_{k j c t} .
$$

The idea behind this specification is that part of the marginal effects on acquired shares captured in the parameter estimates of equation 3.3 might be driven by changes in the prevalence of majority acquisitions (i.e. the extensive margin) during crises. This part of the effect is captured by the "majority" dummy $D_{m a j}$. The coefficient $\beta_{C, F}^{I n t}$ then captures the remaining effect, that is the effect driven by changes within 
the group of non-majority (1\%-49\%) acquisitions and within the group of majority acquisitions (50\%-100\%).

Based on Proposition 1 and the earlier discussion, we frame a key empirical hypothesis regarding the coefficients associated with the dummy variable interactions $D_{C}^{c t} \times D_{F}^{k j c t}$ in equations 3.3, 3.4, and 3.5.

Hypothesis 1 Financial crises have differential effects on ownership structures chosen by domestic and foreign acquirers. Specifically, crises should have a larger effect on domestic stakes in comparison to foreign stakes during crisis times, i.e., $\beta_{C, F}^{\text {Tot. }}<0$. This is driven by both extensive and intensive margins, i.e., $\beta_{C, F}^{E x t .}<0$ and $\beta_{C, F}^{\text {Int. }}<0$.

The crisis effect for domestic acquisitions is $\beta_{C}$ and those for foreign acquisition is $\beta_{C}+\beta_{C, F}$. We expect the crisis effect to differ for domestic and foreign acquisitions, since the latter are presumably unaffected by local credit conditions. In particular, we expect the crisis effect to be larger for domestic acquisitions, i.e., $\beta_{C}+\beta_{C, F}-\beta_{C}=\beta_{C, F}<0$. This, in turn, is driven by changes along an extensive margin (relative decline in the share of high-value acquisitions for foreign acquirers), and an intensive margin (relative decline in stakes acquired within the category of low and high value acquisitions for foreign acquirers).

We estimate the three regressions (equations 3.3, 3.4, and 3.5) by OLS, using our EME data (Panel A of Table 2) and using simulated data from the theoretical model (Panel B of Table 2). Columns (1)-(3) of both panels of Table 2 correspond, respectively, to equations 3.3 - 3.5, and form our baseline results. The column headings indicate which of the margins described above ("Tot." for Total, "Ext." for Extensive and "Int." for Intensive) the coefficients correspond to. First, in qualitative terms, note from Panel A that we find strong empirical support for our key hypothesis: We find in column 1 that the crisis effect is larger for domestic acquisitions than foreign ones $\left(\beta_{C, F}^{T o t}<0\right.$, Hypothesis 1$)$. We find in columns 2 and 3 that the estimates for the extensive margin $(-0.09)$ and the intensive margin $(-0.02)$ are both of the correct sign and statistically significant (at the $1 \%$ and $5 \%$ level, respectively).

The estimated effects are also large quantitatively. During normal times, both domestic and foreign firms acquire on average about a $65 \%$ share in their targets, while roughly $65 \%$ of their acquisitions comprise majority acquisitions in which at least $50 \%$ of a target is acquired. Starting from no statistically significant differences during normal times (as indicated by the zero coefficients on $D_{F}$ in column 1 of Panel A) there is a divergence in the share acquired by 7 percentage points (pp.), driven by an increase of about $5 \mathrm{pp}$. (significant at 1\%) for domestic acquirers and a $2 \mathrm{pp}$. decline (significant at $5 \%$, calculation not shown) for foreign acquirers. Stated differently, domestic and foreign firms acquire roughly similar shares during normal times, while domestic firms acquire about $11 \%$ more ownership during banking crises. The divergence in the likelihood of completing majority acquisitions is even larger, about $15 \% .{ }^{24}$ Columns

\footnotetext{
${ }^{24}$ It should be noted that these baseline estimates form a lower bound in that they control for macroeconomic conditions and fixed effects. Table B.1 in the appendix, which is discussed later, shows the results without these controls. According to these
} 
Table 2: Decomposition of Ownership Stake Changes During Crises

\begin{tabular}{|c|c|c|c|c|c|}
\hline & \multicolumn{3}{|c|}{$\begin{array}{l}\text { Baseline } \\
\text { Results }\end{array}$} & \multicolumn{2}{|c|}{$\begin{array}{c}\text { Alternative Definition } \\
\text { of High-Value }\end{array}$} \\
\hline & \multicolumn{5}{|c|}{ Panel A: SDC Data } \\
\hline & Tot. & Ext. $(50 \%)$ & Int. $(50 \%)$ & Ext. $(100 \%)$ & Int. $(100 \%)$ \\
\hline$\beta_{C}$ & $\begin{array}{l}0.05^{a} \\
(0.01)\end{array}$ & $\begin{array}{l}0.06^{a} \\
(0.01)\end{array}$ & $\begin{array}{l}0.01^{c} \\
(0.00)\end{array}$ & $\begin{array}{l}0.05^{a} \\
(0.01)\end{array}$ & $\begin{array}{l}0.02^{a} \\
(0.00)\end{array}$ \\
\hline$\beta_{F}$ & $\begin{array}{l}-0.01 \\
(0.01)\end{array}$ & $\begin{array}{c}0.00 \\
(0.01)\end{array}$ & $\begin{array}{l}-0.01^{a} \\
(0.00)\end{array}$ & $\begin{array}{l}-0.00 \\
(0.01)\end{array}$ & $\begin{array}{l}-0.00 \\
(0.00)\end{array}$ \\
\hline$\beta_{C, F}$ & $\begin{array}{l}-0.07^{a} \\
(0.01)\end{array}$ & $\begin{array}{l}-0.09^{a} \\
(0.02)\end{array}$ & $\begin{array}{l}-0.02^{b} \\
(0.01)\end{array}$ & $\begin{array}{l}-0.10^{a} \\
(0.02)\end{array}$ & $\begin{array}{l}-0.02^{b} \\
(0.01)\end{array}$ \\
\hline$\beta_{50 \%}$ & & & $\begin{array}{l}0.62^{a} \\
(0.00)\end{array}$ & & \\
\hline$\beta_{100 \%}$ & & & & & $\begin{array}{l}0.59^{a} \\
(0.00)\end{array}$ \\
\hline $\begin{array}{l}\text { No. obs. } \\
R^{2}\end{array}$ & $\begin{array}{c}28,019 \\
0.08\end{array}$ & $\begin{array}{c}28,019 \\
0.06\end{array}$ & $\begin{array}{c}28,019 \\
0.76\end{array}$ & $\begin{array}{c}28,019 \\
0.08\end{array}$ & $\begin{array}{c}28,019 \\
0.73\end{array}$ \\
\hline
\end{tabular}

Panel B: Simulated Data

\begin{tabular}{lccccc} 
& Tot. & Ext. (50\%) & Int. (50\%) & Ext. (100\%) & Int. (100\%) \\
\hline \multirow{6}{*}{$\beta_{C}$} & $0.03^{a}$ & $0.01^{a}$ & $0.02^{a}$ & $0.02^{a}$ & $0.02^{a}$ \\
& $(0.00)$ & $(0.00)$ & $(0.00)$ & $(0.00)$ & $(0.00)$ \\
$\beta_{F}$ & $-0.11^{a}$ & $-0.14^{a}$ & $-0.01^{a}$ & $-0.08^{a}$ & $-0.07^{a}$ \\
& $(0.00)$ & $(0.00)$ & $(0.00)$ & $(0.00)$ & $(0.00)$ \\
$\beta_{C, F}$ & $-0.07^{a}$ & $-0.06^{a}$ & $-0.03^{a}$ & $-0.06^{a}$ & $-0.04^{a}$ \\
& $(0.00)$ & $(0.00)$ & $(0.00)$ & $(0.00)$ & $(0.00)$ \\
$\beta_{50 \%}$ & & & $0.69^{a}$ & & \\
& & & $(0.00)$ & & \\
$\beta_{100 \%}$ & & & & & \\
& & & & & \\
No. obs. & 300,000 & 300,000 & 300,000 & 300,000 & 300,000 \\
$R^{2}$ & 0.04 & 0.11 & 0.31 & 0.01 & 0.66 \\
& & & & & \\
\hline
\end{tabular}

Notes: The table reports the point estimate of the coefficient associated with the banking crisis dummy $\beta_{C}$, foreign acquisition dummy $\beta_{F}$ and their interaction $\beta_{C, F}$ obtained from an OLS estimation on the SDC dataset (Panel A) and simulated data (Panel B). For both panels, the precise specifications in columns 1-3 are as follows. Column (1) corresponds to equation 3.3; column (2) corresponds to equation 3.4; column (3) corresponds to equation 3.5. Column (4) is an alternative of the specification in column (2) with the dependent variable defined on the basis of a dummy variable that is 1 when $100 \%$ of a firm is acquired in an acquisition. Column (5) estimates the specification in column (1) on the subset of acquisitions in which less than $100 \%$ of a firm is acquired. Conceptually, it is a counterpart of the specification in column (3). See the text of the paper for detailed explanations. $a, b$ and $c$ indicate statistical significance at the $1 \%, 5 \%$ and $10 \%$ levels, respectively. Robust standard errors reported in parentheses. All columns in Panel A have macroeconomic controls and country $\times$ target-industry fixed effects, the coefficients of which are omitted from the table to conserve space. 
1-3 together suggest that the mechanisms highlighted by our theoretical analysis - that of an extensive margin compositional shift towards high-value majority acquisitions $\left(\beta_{C, F}^{E x t}\right.$ in column 2$)$ and a selection effect along the intensive margin $\left(\beta_{C, F}^{I n t}\right.$ in column 3$)$ - are significant determinants of the divergence in ownership between constrained domestic acquiring firms and unconstrained foreign firms captured by $\beta_{C, F}^{T o t}$ in column 1.

Table 2 also highlights the benefits of our DID approach: The DID crisis effects, which compares the crisis effect on constrained (domestic) acquirers to the crisis effect on unconstrained (foreign) acquirers, are 7 pp., 9 pp. and 2 pp. for the total effect, the extensive margin and the intensive margin, respectively. In comparison, the coefficients $\beta_{C}^{\text {Tot. }}=0.05, \beta_{C}^{E x t}=0.06$ and $\beta_{C}^{\text {Int. }}=0.01$ in Panel A of Table 2, which only compare domestic firms between crisis and normal times, are smaller in magnitude. ${ }^{25}$ Thus, not taking into account the effects of the change in the pool of target firms during financial crises which in our estimates is captured by the comparison to a baseline of unconstrained foreign acquirers underestimates the effect that acquirer-side financial constraints have on ownership shares.

To compare the model's predictions to the empirical results in quantitative terms, we present in Panel B of Table 2 the coefficients from identical estimations performed on a data set with a total of 300,000 observations simulated using the procedure outlined in the previous section. For completeness we report the same set of statistics in Panels A and B, such as the number of observations and standard errors. However we focus only on the point estimates of the coefficients from the simulated data. ${ }^{26}$ Looking at column 1 , Panel B, we see that the simulated crisis leads to an increase of the share acquired by domestic acquisitions of 3 percentage points, but a decrease for foreign acquisitions by 4 percentage points, implying again a gap of 7 pp., as in the data. Note that these numbers are consistent with the simulation results conveyed in Figure 3. The predicted signs and magnitudes of the coefficients are remarkably similar in the simulated and actual data for such a parsimonious model. ${ }^{27}$ Decomposing the effect into an extensive and intensive

estimates, while domestic and foreign firms acquire roughly similar shares during normal times, domestic firms acquire about $15 \%$ more ownership during banking crises and are about $18 \%$ more likely to complete majority acquisitions.

${ }^{25}$ An alternative way to estimate the crisis effect on domestic acquirers alone is by dropping all the foreign acquisitions from our data and running the following two regressions on the subset of acquisitions made by domestic acquirers only:

$$
\begin{array}{r}
\text { fracacq }_{k j c t}=\beta_{0}^{T o t .}+\beta_{C}^{T o t .} D_{C}^{c t}+\operatorname{con}^{\prime} \boldsymbol{\beta}_{\text {con }}+\epsilon_{k j c t} \\
D_{m a j .}^{k j c t}=\beta_{0}^{E x t .}+\beta_{C}^{E x t .}+\boldsymbol{c o n}^{\prime} \boldsymbol{\beta}_{\text {con }}+\epsilon_{k j c t} \\
\text { fracacq }_{k j c t}=\beta_{0}^{I n t .}+\beta_{C}^{I n t .} D_{C}^{c t}+\beta_{m a j .} D_{m a j}^{k j c t}+\operatorname{con}^{\prime} \boldsymbol{\beta}_{\text {con }}+\epsilon_{k j c t} .
\end{array}
$$

This leads to point estimates (results not shown) of $\beta_{C}^{T o t .}=0.04, \beta_{C}^{E x t}=0.06$, and $\beta_{C}^{I n t}=0.005$. i.e., 4 pp., 6 pp. and approximately $1 \mathrm{pp}$. changes in the total, extensive and intensive margins.

${ }^{26}$ The point estimates are effectively the coefficients from a linear approximation of the data generating process implied by the theoretical model, and are meant to provide a sense of the quantitative performance of the model. We do not have data that would let us precisely calibrate all the stochastic processes used in the simulations, for example, the variance of firm-specific idiosyncratic shocks. Since these influence all the objects estimated in the regression with the simulated data, we do not compare all the estimated statistics, e.g. standard errors, to the corresponding statistics from the SDC regressions.

${ }^{27}$ One caveat to this particular comparison between the model and the data is that we do not calibrate our financial friction 
margin (columns 2 and 3), we find that the intensive margin plays a somewhat more important role in the simulated data than the actual data. ${ }^{28}$

A cut-off ownership of $50 \%$ defines high-value acquisitions in our baseline regression results reported in columns 1-3, based on the results of Chari, Ouimet and Tesar (2010). We also report results for an alternative where the cut-off ownership for high-value acquisitions is $100 \%$, that takes into account the industry-level positive correlation between target productivity and the likelihood of $100 \%$ acquisitions reported in Alquist et al. (2017). Accordingly, we re-estimate an alternative of the specification in column 2 with the dependent variable being an indicator that is 1 when $100 \%$ of a firm is acquired in an acquisition (column 4 of Panels A and B). Corresponding intensive margins are shown in column 5 using the specification in column 3 , but using an indicator variable for $100 \%$ acquisitions (instead of $\geq 50 \%$ acquisitions as in column 3). Overall, both definitions of high-value acquisitions yield similar results. Our empirical analysis of divestiture decisions utilizes this alternative definition of a high-value acquisition for reasons that are clarified in the following section.

\subsubsection{Divestiture Rates: Empirical Strategy, Hypotheses and Results}

Our model also has predictions on the subsequent resale of acquisitions. To remind the reader, Proposition 2 looked at the differential effect of a financial shock on the divestiture rates of constrained domestic and unconstrained foreign acquisitions. The motivation for focussing on the differential is the same as that for the acquired share, which is that a DID procedure is better able to isolate the effects of acquirer financial constraints. In particular, Proposition 2 predicted that the differential flip rate ("constrained" minus "unconstrained") would decline. To test Proposition 2 empirically, we estimate a Cox proportional hazards model of the following form:

$$
\ln \left[h_{k j c}(\tau \mid \cdot)\right]=\ln \left[h_{j c}(\tau)\right]+\beta_{C} D_{C}^{c t}+\beta_{F} D_{F}^{k j c t}+\beta_{C, F} D_{C}^{c t} \times D_{F}^{k j c t}+\text { controls }{ }_{c, t-4}^{\prime} \beta_{m c}+\epsilon_{k j c t} .
$$

parameter $\tau$, but simply model the aggregate financial shock as a decline in $\tau$ from 0.75 to 0.6 , resulting in a 25 percent decline in the maximum debt-to-value ratio of all firms. Both the initial value of $\tau$ and its drop determine the DID coefficient $\beta_{C, F}$, as can be seen in Figure 4a. It is, however, remarkable that both the data and the model suggest that this DID effect is driven to roughly the same extent by an increase in the share acquired by domestic firms and a decrease in the share acquired by foreign firms.

${ }^{28}$ The reader might notice that the magnitude of the coefficient associated with the foreign dummy $\beta_{F}$ is clearly negative, in contrast to a near zero coefficient in the data. Our model therefore implies that foreign acquisitions are somewhat smaller than domestic acquisitions during normal times. This is not too surprising because our model assumes that foreign and domestic acquirers only differ in their access to finance. Low-synergy (and hence, small-share) acquisitions are not feasible for domestic, constrained acquirers in our model, even in normal times. One could easily align the model's predicted $\beta_{F}$ with that found in the data by assuming that foreign and domestic acquirers also vary along other dimensions, such as in the distribution of synergy parameters. This modification, however, would have little effect on the model's predictions about our main coefficient of interest, $\beta_{C, F}$. 
where $D_{C}^{c t}, D_{F}^{k j c t}$ and the controls are defined as in the previous section. ${ }^{29}$ The estimated hazard function, $h_{j c}(\tau)$, is the probability density that the average firm experiences an acquisition event in a small interval of time $\Delta \tau$, conditional on it not having been the target of an acquisition for $\tau$ units of time since the last acquisition event (see Kalbfleisch and Prentice, 1980, for details of the notation). We stratify this baseline hazard $h_{j c}(\tau)$ at the country $\times$ target-industry level (i.e., allowed to be different across countries indexed $c$ and industries indexed $j$ ), to be consistent with the country $\times$ target-industry fixed effects in the regression analysis of acquired shares. The purpose of the stratification is to take into account divestiture patterns that might be unique to certain countries and industries, say due to regulations.

For our baseline estimations, the duration $\tau$ of an acquisition is measured as follows. We identify target firms that appear at least twice in our data. Let such a target firm be indexed by $k$. The first transaction involving $k$ identifies the beginning of the relationship between the first acquirer and the target. The second transaction involving $k$ is assumed to mark the end of the immediately preceding ownership relationship, and so on for subsequent appearances by the same target $k$ in the data. ${ }^{30}$ The duration of acquisitions involving target $k$ is then defined as the distance in time between each transaction involving $k$. While this scheme has the serious limitation that an acquisition event involving $k$ always assumes the seller of the stake to be the previous acquiring firm (which may not be the case due to partial ownership), it has two advantages. First, it lets us keep the same sample of firms for which we estimated our ownership regressions. Second, it makes the performance of the theoretical model easier to compare to the data for reasons that are explained later. However, we also use an alternative scheme that is immune to the issue described above as a robustness check.

In the model above, the hazard ratio $\frac{h_{k j c}(\tau \mid X)}{h_{j c}(\tau)}$ is the ratio between the hazard rate when the covariates take values summarized by the vector $X$, and the baseline hazard. Our main hypothesis from Proposition 2 is that the crisis effect should lead to a relative decline of flipping rates of the crisis cohort of domestic acquisitions, or a relative increase in the flipping rates of foreign cohort. That is, the coefficient $\beta_{C, F}$ in 3.6 should be positive.

Hypothesis 2 Financial crises have differential effects on flip rates of the crisis cohort of domestic and foreign acquisitions. Specifically, the differential flip rate for the crisis cohort of foreign acquisitions will increase, i.e., $\beta_{C, F}>0$. Equivalently, the exponentiated coefficient, which shows the differential effect in percentage terms should be greater than unity, i.e., $e^{\beta_{C, F}}>1$.

The results of estimating equation 3.6 are shown in column 1 of Table 3. For ease of exposition the

\footnotetext{
${ }^{29}$ The Cox model is a semi-parametric model where the baseline hazard is non-parametric (and in our case different in each country-sector) while the estimated log hazard rate is assumed to be log-linearly related to the covariates. In other words, each baseline log hazard function is shifted by the same magnitude by changes in given covariates.

${ }^{30}$ Our data does not allow us to identify the direct seller of a share in a transaction.
} 
Table 3: Hazard Ratios From Cox Model

\begin{tabular}{|c|c|c|c|c|c|c|c|}
\hline & \multicolumn{3}{|c|}{ Baseline Results ${ }^{1}$} & & \multicolumn{3}{|c|}{ Robustness Checks ${ }^{2}$} \\
\hline & (1) & (2) & (3) & & (4) & (5) & $(6)$ \\
\hline$e^{\beta_{C}}$ & $\begin{array}{l}0.81^{b} \\
(0.08)\end{array}$ & $\begin{array}{l}0.84^{c} \\
(0.08)\end{array}$ & $\begin{array}{l}0.86^{c} \\
(0.08)\end{array}$ & $e^{\beta_{C}}$ & $\begin{array}{l}0.76^{c} \\
(0.11)\end{array}$ & $\begin{array}{l}0.78^{b} \\
(0.09)\end{array}$ & $\begin{array}{l}0.78^{c} \\
(0.11)\end{array}$ \\
\hline$e^{\beta_{F}}$ & $\begin{array}{c}0.90 \\
(0.07)\end{array}$ & $\begin{array}{l}0.85^{b} \\
(0.06)\end{array}$ & $\begin{array}{c}0.89 \\
(0.07)\end{array}$ & $e^{\beta_{F}}$ & $\begin{array}{l}0.82^{b} \\
(0.07)\end{array}$ & $\begin{array}{c}0.86^{c} \\
(0.07)\end{array}$ & $\begin{array}{c}0.89 \\
(0.09)\end{array}$ \\
\hline$e^{\beta_{C, F}}$ & $\begin{array}{l}1.31^{b} \\
(0.16)\end{array}$ & $\begin{array}{c}1.19 \\
(0.14)\end{array}$ & $\begin{array}{c}1.19 \\
(0.17)\end{array}$ & $e^{\beta_{C, F}}$ & $\begin{array}{c}1.12 \\
(0.22)\end{array}$ & $\begin{array}{c}1.06 \\
(0.19)\end{array}$ & $\begin{array}{c}0.90 \\
(0.20)\end{array}$ \\
\hline$e^{\beta_{50 \%}}$ & & $\begin{array}{l}0.23^{a} \\
(0.01)\end{array}$ & $\begin{array}{l}0.24^{a} \\
(0.02)\end{array}$ & $e^{\beta_{100 \%}}$ & & $\begin{array}{l}0.17^{a} \\
(0.01)\end{array}$ & $\begin{array}{l}0.17^{a} \\
(0.02)\end{array}$ \\
\hline$e^{\beta_{C, 50 \%}}$ & & & $\begin{array}{c}0.96 \\
(0.12)\end{array}$ & $e^{\beta_{C, 100 \%}}$ & & & $\begin{array}{c}1.00 \\
(0.21)\end{array}$ \\
\hline$e^{\beta_{F, 50 \%}}$ & & & $\begin{array}{c}0.91 \\
(0.08)\end{array}$ & $e^{\beta_{F, 100 \%}}$ & & & $\begin{array}{c}0.91 \\
(0.15)\end{array}$ \\
\hline$e^{\beta_{C, F, 50 \%}}$ & & & $\begin{array}{c}0.99 \\
(0.19)\end{array}$ & $e^{\beta_{C, F, 100 \%}}$ & & & $\begin{array}{c}1.53 \\
(0.53)\end{array}$ \\
\hline No. obs. & 28,019 & 28,019 & 28,019 & No. obs. & 19,329 & 19,329 & 19,329 \\
\hline $\log L$ & $-20,336.8$ & $-19,414.8$ & $-19,413.7$ & $\log L$ & $-7,117.0$ & $-6,630.9$ & $-6,629.7$ \\
\hline
\end{tabular}

Notes: ${ }^{1}$ The table reports baseline results for the estimated hazard ratios associated with the banking crisis dummy $D_{C}$, foreign acquisition dummy $D_{F}$, a dummy for $50 \%$ acquisitions $D_{50 \%}$, and their interaction terms obtained from a Cox duration model. All three columns (1)-(3) are based on the sample of acquisitions by domestic and foreign acquirers in which at least $10 \%$ is acquired.

${ }^{2}$ The table also reports robustness results for the estimated hazard ratios associated with the banking crisis dummy $D_{C}$, foreign acquisition dummy $D_{F}$, a dummy for $100 \%$ acquisitions $D_{100 \%}$, and their interaction terms obtained from a Cox duration model. All three columns (4)- (6) are based on the sample of acquisitions by domestic and foreign acquirers in which at least $51 \%$ is acquired.

Columns (1) \& (4), (2) \& (5), and (3) \& (6), correspond respectively to regression equations 3.6, 3.8 and 3.9 in the text, exponentiated to express them in terms of hazard ratios. The baseline hazards are stratified by country $\times$ target-industry. The dates for the domestic banking crises are from Laeven and Valencia (2010). $a, b$ and $c$ indicate statistical significance at the $1 \%, 5 \%$ and $10 \%$ levels, respectively. Standard errors clustered at the level of country $\times$ target-industry are reported in parentheses. All columns include macroeconomic controls whose coefficient estimates are omitted from the table to conserve space. 
table displays the exponent of the coefficient, e.g. $e^{\beta_{C, F}}$ instead of $\beta_{C, F} \cdot{ }^{31}$ Values above one then indicate an increase in the hazard rate, and values below one indicate a decrease in the hazard.

We find evidence in favor of Hypothesis 2: The point estimate of the hazard ratio corresponding to the coefficient $e^{\beta_{C, F}}$ is 1.31 , significant at $5 \%$. This implies that the effect of the crisis on the flipping rates of the crisis cohorts of domestic and foreign acquisitions are statistically different, in the direction predicted by the theory. The subsequent flip rate for foreign acquisitions undertaken during crises goes up by $\left(e^{\beta_{C, F}}-1\right) \times 100=31 \%$ compared to the flip rate for domestic acquisitions.

To better understand this empirical result we turn again to Proposition 2, which decomposed the differential effect of the crisis in flipping rates as follows,

$\Delta\left(\frac{n^{f l i p}}{n}-\frac{n^{f l i p^{*}}}{n^{*}}\right)=\underbrace{\Delta \omega}_{\Delta \text { normal flip }(=0)}+\underbrace{\Delta(1-p)(1-\omega)}_{\Delta \text { forced flip }(<0)}-\underbrace{\Delta \omega^{*}}_{\Delta \text { normal flip }(>0)}<0 \quad\left(\right.$ when $\left.\Delta \tau_{1}<0\right)$,

into changes of the "normal" and "forced" flip rates for domestic acquirers, and the change in the "normal" flip rate for foreign acquirers. Proposition 2 predicted that there is no change in the proportion of normal flips for domestic acquirers (since there is no change in the proportion of low-value domestic acquisitions) under particular assumptions about the distribution of synergies and financial liquidity. At the same time it predicted that the differential (foreign - domestic) flip rate would increase, driven by the decline of domestic forced flips and the increase of foreign normal flips.

First, we establish whether the behavior of domestic or foreign flips drives the empirical evidence in favor of Proposition 2. In terms of the Cox regression hazard ratios in Table 3, a decline in the flip rate of the crisis cohort of domestic acquisitions would imply a corresponding hazard ratio of $e^{\beta_{C}}<1$, and an increase in the flip rate of the crisis cohort of foreign acquisitions would imply $e^{\beta_{C}+\beta_{C, F}}>1$. Column 1 of Table 3 shows that $e^{\beta_{C}}=0.81$, statistically significant at the $5 \%$ level, meaning that the subsequent flip rates of domestic acquisitions are lower by $\left(1-e^{\beta_{C}}\right) \times 100=19 \%$ when conducted during crises. At the same time $e^{\beta_{C}+\beta_{C, F}}=1.06$, which suggests that the flip rate for foreign acquisitions do increase as predicted by the theory. But the change is small, about $\left(1-e^{\beta_{C}+\beta_{C, F}}\right) \times 100=6 \%$, and not statistically

\footnotetext{
${ }^{31}$ To elaborate, the model in equation 3.6 can be expressed in terms of hazard ratios as $h_{k j c}(\tau \mid \cdot)=$

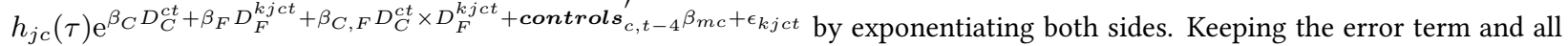
control variables fixed at 0 to ease exposition, the baseline hazard $h_{j c}(\tau)$ is the hazard rate (h.r.) for the normal cohort of domestic acquisitions; the h.r. of the crisis cohort of domestic acquisitions is $h_{j c}(\tau) \mathrm{e}^{\beta_{C}}$; the h.r. for the normal cohort of foreign acquisitions is $h_{j c}(\tau) \mathrm{e}^{\beta_{F}}$; and the h.r. for the crisis cohort of foreign acquisitions is $h_{j c}(\tau) \mathrm{e}^{\beta_{C}+\beta_{F}+\beta_{C, F}}$. Hence the difference in the crisis effect between foreign and domestic acquisitions (i.e., the DID effect) is $\frac{\frac{h_{j c}(\tau) \mathrm{e}^{\beta_{C}+\beta_{F}+\beta_{C, F}}}{h_{j c}(\tau) \mathrm{e}^{\beta} F}}{\frac{h_{j c}(\tau) \mathrm{e}^{\beta} C}{h_{j c}(\tau)}}=\mathrm{e}^{\beta_{C, F}}$ in proportional terms, which is hypothesized to be greater than 1. See Table B.8 in the appendix that displays the regression coefficients associated with the hazard ratios in Table 3.
} 
significant. ${ }^{32}$ Hence, we conclude that the empirical evidence in favor of Proposition 2 is driven mostly by a decline in the average flip rates of the crisis cohort of domestic acquisitions.

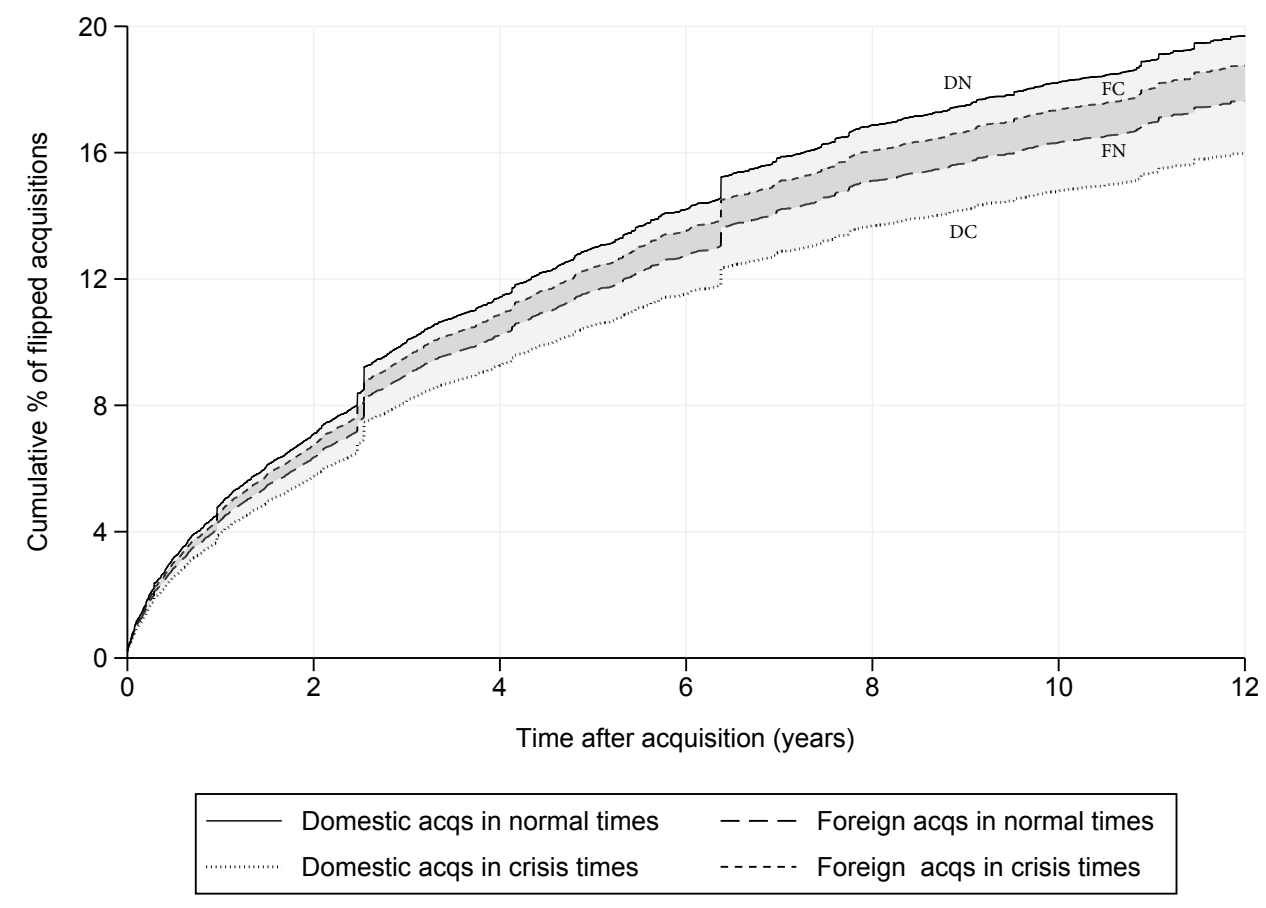

Figure 5: Estimated share of flipped acquisitions from Cox regression

Notes: The figure displays the cumulative proportion of flipped acquisitions with respect to the time after acquisition based on the estimated coefficients of the stratified Cox proportional hazards model in Column (1) of Table 3. The adjusted baseline cumulative hazard function, corresponding to the curve for domestic acquisitions in normal times, is obtained from a weighted average of the baseline hazard functions across target country $\times$ industry strata, with the weights proportional to the number of flipped acquisitions at the given level of stratum.

The estimated hazard ratios in Table 3 are informative about the magnitudes of the effects of the individual covariates in comparison to the baseline hazards, but do not tell us anything about the actual flip rates. For further comparison to the theoretical model, Figure 5 therefore plots the cumulative proportion of acquisitions flipped predicted from the Cox estimation above as a function of the number years since the acquisition. The four lines on the figure correspond to the four categories of acquisitions that are of

\footnotetext{
${ }^{32}$ To test statistically whether $e^{\beta_{C}+\beta_{C, F}}$ is different from 1 , we conduct a test of significance for the linear combination of coefficients in the Cox regression. We find that the point estimate of $\beta_{C}+\beta_{C, F}$ is 0.06 with a standard error of 0.09 , so that $e^{\beta_{C}+\beta_{C, F}} \approx 1.06$.
} 
interest - domestic-normal (DN), domestic-crisis (DC), foreign-normal (FN) and foreign-crisis (FC). The empirical estimates indicate that the flip rates of the crisis cohort of domestic acquisitions are lower at all horizons (the cumulative flip cure shifts down from DN to DC), while the flip rates of the crisis cohort of foreign acquisitions are higher at all horizons (the cumulative flip cure shifts up from FN to FC).

Recall that Figure 4 in the simulation section displayed flipping rates for constrained and unconstrained acquirers as a function of the borrowing constraint parameter, $\tau$. The crisis was modelled as a change in this parameter from 0.75 to 0.6 , and then reversion to its normal value of 0.75 after the crisis. For the chosen parameters, the simulations of the model predicted an increase of the flipping rates for unconstrained acquirers by 6 percentage points from $11.5 \%$ to $17.2 \%$, and a decrease for constrained acquirers from $18.5 \%$ to $16.3 \%$, both over a period of roughly 4 years since the date of the acquisition. In contrast, the empirical results show that the percentage of foreign acquisitions flipped at the 4-year horizon increases from $10.2 \%$ to $10.9 \%$ for the normal versus the crisis cohort (16.3\% to $17.4 \%$ for a 10 -year horizon), while the same figure for domestic acquisitions declines from $11.4 \%$ to $9.3 \%$ for the normal versus the crisis cohort (18.2\% to $14.8 \%$ for a 10 -year horizon). Comparing the magnitudes of the cumulative fractions of acquisitions flipped in Figures 5 and 4, three points stand out. First, the theoretical model overestimates the levels of the flip rates at the 4-year horizon for which the model is calibrated. Second, the theory underestimates the change in the flip rates of domestic (constrained) acquisitions and overestimates the change in the flip rates of foreign (unconstrained) acquisitions. Third, the magnitude of the changes in the flip rates predicted by the model are more consistent with empirical flip rates at longer horizons.

Next, we ask whether it is changes in normal flips or changes in forced flips that drive the $19 \%$ decline in domestic divestiture rates found in column 1. From the decomposition in equation 3.7, it can be seen that lower flipping for constrained domestic acquirers can be in principle due to fewer normal flips driven by a compositional shift towards high-value acquisitions (though under the distributional assumptions in Proposition 2 this change is 0 ), as well as fewer liquidity-based forced flips. We attempt to disentangle these two channels by using a majority acquisition as the empirical counterpart for a high-value acquisition, as in our baseline estimates for ownership acquired. ${ }^{33}$ The idea is to control in regression 3.6 for the compositional shift towards high-value acquisitions. If our estimate of the hazard ratio $e^{\beta_{C}}$ remains unaffected by this control, we interpret this as evidence that part of the reducing flipping rate is driven by fewer forced flips. Accordingly, we add to the model of equation 3.6 a dummy independent variable $D_{50 \%}^{k j c t}$ indicating whether a transaction resulted in majority ownership:

$\ln \left[h_{k j c}(\tau \mid \cdot)\right]=\ln \left[h_{j c}(\tau)\right]+\beta_{C} D_{C}^{c t}+\beta_{F} D_{F}^{k j c t}+\beta_{C, F} D_{C}^{c t} \times D_{F}^{k j c t}+$ controls $\boldsymbol{s}_{c, t-4}^{\prime} \beta_{m c}+\beta_{50 \%} D_{50 \%}^{k j c t}+\epsilon_{k j c t}$.

\footnotetext{
${ }^{33}$ As explained earlier, this builds on the idea in Chari, Ouimet and Tesar (2010) that majority acquisitions create real value gains in emerging markets for both domestic and foreign acquirers.
} 
The results of estimating equation 3.8 are shown in column 2 of Table 3 . We find evidence that the decline in the flipping rate for domestic acquirers is driven by both a decline in forced flips and a decline in normal flips. First, though the hazard ratio $e^{\beta_{C}}$ in column 2 declines somewhat in magnitude (indicating a $16 \%$ decline in domestic flip rates, as opposed to $19 \%$ in column 1), it remains statistically significant at $10 \%$. Thus, to the extent that the full ownership dummy proxies for high-value acquisitions, controlling for the compositional shift towards high value acquisition keeps our qualitative results unchanged. Through the lens of our theoretical model, we interpret this result as evidence that there are fewer liquidity-based forced flips for the crisis cohort of domestic acquisitions. Second, part of the decline in the flipping rates can be explained by a compositional shift. The highly statistically significant hazard ratio associated with $D_{50 \%}^{k j c t}$ in column 2 shows that majority acquisitions indeed have lower divestiture rates (77\% lower on average), consistent with the behavior of high-value acquisitions in the model. This result, coupled with our earlier finding that there is an extensive margin shift towards full acquisitions for domestic acquirers (column 4 of Table 2), suggests that part of the lower divestiture rate identified in column 1 of Table 3 is driven by the first channel in the model, which is, a decline in normal flips due to a shift towards highvalue acquisitions that are less likely to be divested. Thus, we find evidence that both channels in equation 3.7 lead to a decline in flips in the cohort of domestic crisis-time acquisitions. ${ }^{34}$

To summarize our empirical results, we find strong empirical support for our predictions regarding the fraction of a firm acquired. Specifically, we find that financially constrained domestic firms in the crisis-hit country acquire between 11-15\% more ownership and are 15-18\% more likely to take majority stakes than their unconstrained foreign counterparts (see our earlier calculations based on columns 1 and 2 in Panel A of Tables 2 and B.1). Such ownership is also more likely to be persistent: the survival rate of a domestic acquisition is between $19-24 \%$ higher in the crisis cohort (from the exponentiated coefficient $e^{\beta_{C}}$ in columns 1 and 4 of Table 3). Thus the evidence on divestiture rates is also consistent with our theoretical predictions, though statistically weaker for certain specifications, and generally favors the mechanisms highlighted by the model.

\subsection{Robustness Checks}

Non-linear estimation: Table B.2 in the appendix shows that the baseline OLS results on shares acquired are robust to estimation using a Generalized Linear Model (GLM). The GLM estimation explicitly accounts for the fact the share acquired, as well as the extensive margin probability, are bounded between 0 and 1.

\footnotetext{
${ }^{34}$ The magnitudes of the hazard ratios $e^{\beta_{F}}$ in the second row of Table 3, columns 1 and 2 ( 0.90 and 0.85 , respectively), are also consistent with the predictions of our model. They indicate that foreign acquisitions completed in normal times have lower divestiture rates than domestic ones, as shown in Figure 4.
} 
Different fixed effects: We further verify (see Table B.1 in the appendix) that the baseline results with macro controls, and target country $\times$ industry fixed effects are robust to having different fixed effect constellations, namely: (i) no fixed effects or macro controls; (ii) macro controls and target country fixed effects; (iii) macro controls, target country, and target industry fixed effects; and (iv) macro controls, target country, and acquirer industry fixed effects. These different specifications control for factors that are discussed below.

Controlling for other determinants: Our baseline regressions control for a number of determinants of acquisitions that have been identified in the literature. It has been shown in the literature that there is normal business cycle variation in M\&As as well as longer-term effects of the general level of development of an economy. Thus, all the regressions with acquired shares as dependent variable, as well as the duration analysis, use the following macroeconomic controls. Real GDP growth (annual) is used to proxy for the business cycle and real GDP per capita (annual) to control for the level of development of the target country. The nominal exchange rate (quarterly) is included to control for the effect of exchange rates on the value of collateral as in Froot (1991) and the use of IMF credit and loans as a percentage of a country's quota (quarterly) to account for stress factors in the balance of payments. ${ }^{35}$ Alquist et al. (2017) find that the external finance dependence of target sectors is a secular determinant of the likelihood of foreign acquisitions and the ownership structures chosen by these acquirers. All our benchmark specifications include SIC single-digit target-industry $\times$ target-country fixed effects to control for such target sector specific effects. Note that this fixed effect specification would also account for differences from the targets being from specific sectors, such as the financial sector.

Controlling for differing motives for domestic and foreign acquirers: Zhu, Jog and Otchere (2011) find evidence that firms in EMEs acquire partial stakes in other domestic firms to gain corporate control, while foreign firms use acquisitions as a strategic tool to enter foreign markets. We control for these possible dynamic differences in motives by controlling for preexisting partial ownership (at the time of an acquisition) of the acquiring firm in the target firm. These results are shown in Table B.3 in the appendix. The table shows that acquirers are likely to acquire smaller stakes when they already own a stake in firm. However, controlling for pre-existing ownership keeps our results unchanged qualitatively. A large literature has recently analyzed the unique characteristics of banking sector acquisitions (see Acharya, Shin and Yorulmazer, 2011a, 2008; Acharya and Viswanathan, 2007, for example) that are driven by the relative opacity of their assets, and the non-pledgable nature of some of their intangible capital (such as customer

\footnotetext{
${ }^{35}$ These variables are introduced in single-period lags, following Brown and Dinc (2011). The sources of these data are the Penn World Tables, the IMF's International Financial Statistics, Taiwan's National Statistical Office, and the Central Bank of the Republic of China.
} 
relationships). Since these characteristics are likely to differ among foreign and domestic acquiring banks, our results might be mainly driven by changes in the importance of financial sector acquisitions during crises. While our acquirer-industry fixed effect specification above should control for the acquirer being from the financial sector, we also include an indicator variable control in our baseline specification for transactions where both acquirer and target are from the financial sector. These additional controls leaves our results unchanged (see Tables B.1, B.4 and B.5 in the appendix). Thus the features we uncover appear to be valid both for financial and non-financial sector acquisitions.

Alternative crisis definitions: We also use an alternative proxy for an aggregate financial shock, making use of the annual banking crisis dates from Reinhart and Rogoff (2009) instead of our baseline dating scheme from Laeven and Valencia (2010). These results are shown in Table B.7 in the appendix. In addition, Table B.6 in the appendix estimates our baseline regressions using only the sample of countries that experienced at least one crisis during 1990-2007 according to Laeven and Valencia (2010), i.e. excluding Chile, Peru, Singapore and South Africa. Our results are insensitive to these alternatives.

Sectoral composition of acquisitions and sectoral heterogeneity in the crisis effect: Since our results are averages over several sectors, they could be rationalized if, during crises, domestic acquirers acquire more often in sectors where acquisitions typically involve larger or controlling stakes, while foreign acquirers do the opposite. Thus a possibility we explore is whether our results are driven by changes in the industry composition of acquisitions during crises. The results of this analysis are reported and discussed in the appendix Section B.1. In summary, we find that changes in the sectoral composition of acquisitions are responsible for at least part of the aggregate effects we find in Table 2. Note that such sectoral composition effects are not ruled out by our theory, the salient feature of which is to posit the existence of general compositional effects without positing where such effects might originate.

Our model is aggregate and as such does not have any implications for sectoral variation in the total crisis effect or the different margins. While our baseline results control for heterogeneity across industries using fixed effects, this does not allow for heterogeneity in the crisis effect. In order to check if the results in Table 2 hold within each industry as well, Section B.1 reports and discusses the results of an analysis of the crisis effect across different industries. We find that the direction of the crisis effects across domestic and foreign acquisitions are broadly consistent with our theory. A large majority of sectors for domestic acquisitions show an increase in shares acquired and majority acquisitions, while the opposite is true for foreign acquisitions. However, the magnitudes and statistical significance of the coefficients paint a picture of wide heterogeneity in effects across sectors. For example, it appears that Mining and Construction, Wholesale and Retail, and Services (education, legal, other) do not contribute notably to the aggregate effects for domestic acquisitions, while the Finance, Insurance, and Real Estate, and the two 
Services sectors are the most important for foreign acquisitions. In summary, we find evidence consistent with our aggregate results for acquired shares being driven both by between-sector compositional effects, as well as within sector changes along the different margins.

Measuring duration in the Cox model: The duration $\tau$ of an acquisition in the baseline regressions was measured by the distance in time between each transaction involving a particular target firm. However, this potentially overestimates change in the flipping rates because partial ownership stakes may be flipped by a different owner than the one involved in the initial transaction. Thus, as a robustness check, we use an alternative definition that is immune to this issue. Along with the fraction of a target acquired in a transaction, our data source provides the fraction of the target that the acquiring firm owns after the transaction. These may be different when the acquirer had prior partial ownership in the target. For the purpose of the robustness check, we first limit our sample to acquisitions in which post-acquisition, the acquiring firm owned $51 \%$ or more of the target. We then identify target firms that appear at least twice in our data. Let such a target firm be indexed by $k$. In the second acquisition involving $k$, it has to be the first acquirer who sold a stake in the target since we limited the sample to acquisitions after which the acquirer owns at least $51 \%$ (since the sum of ownership shares cannot exceed $100 \%$ ). The initial transaction thus identifies the beginning of the relationship between the first acquirer and the target. The second sale is assumed to mark the end of the immediately preceding ownership relationship, and so on for subsequent appearances by the same target in the data. The duration of acquisitions involving target $k$ is thus the distance in time between each transaction involving $k$ that resulted in a stake of at least $51 \%$. Since we only use the subsample of acquisitions in which the acquiring firm owned $51 \%$ or more of the target postacquisition in the hazard estimation, we proxy for high value acquisitions with full acquisitions instead of majority acquisitions in this case. The results of this alternative estimation are shown in columns 4-6 of Table 3. The results are consistent across the two definitions of duration. In fact the point estimates of the hazard ratios show a somewhat larger decline of $24 \%$ in the hazard rates of domestic flips.

Assumption about high-value acquisitions in the Cox model: An implication of the model's assumption that high-value acquisitions by constrained domestic and unconstrained foreign acquirers were fundamentally similar was that the low flip rates of high-value acquisitions should not differ across these two types of acquisitions, nor be influenced by the crisis itself. To test whether these assumptions hold in the data we augment the Cox model in equation 3.8 with interaction terms between $D_{50 \%}^{k j c t}$ (or $D_{100 \%}^{k j c t}$ for the alternative scheme described above), $D_{C}^{c t}$ and $D_{F}^{k j c t}$ :

$$
\begin{aligned}
\ln \left[h_{k j c}(\tau \mid \cdot)\right] & =\ln \left[h_{j c}(\tau)\right]+\beta_{C} D_{C}^{c t}+\beta_{F} D_{F}^{k j c t}+\beta_{C, F} D_{C}^{c t} \times D_{F}^{k j c t}+\beta_{50 \%} D_{50 \%}^{k j c t} \\
& + \text { controls } s_{c, t-4}^{\prime} \beta_{m c}+\text { interaction terms }+\epsilon_{k j c t} .
\end{aligned}
$$


where the vector of interaction terms comprises $D_{C}^{c t} \times D_{50 \%}^{k j c t}, D_{F}^{k j c t} \times D_{50 \%}^{k j c t}$ and $D_{C}^{c t} \times D_{F}^{k j c t} \times D_{50 \%}^{k j c t}$. The results of estimating the hazard ratios from the model above are shown in columns 3 and 6 of Table 3 (corresponding coefficients are reported in Table B.8 in the appendix). The additional hazard ratios associated with the interaction terms of $D_{50 \%}^{k j c t}\left(D_{100 \%}^{k j c t}\right)$ in column 3 (column 6) are statistically indistinguishable from unity (i.e., the corresponding coefficients are statistically indistinguishable from zero), and the coefficients on $D_{50 \%}^{k j c t}\left(D_{100 \%}^{k j c t}\right)$ themselves do not change much across columns 2 and 3 ( 5 and 6 ). This shows that $50 \%$ (or $100 \%$ ) acquisitions are less likely to be flipped irrespective of whether they are undertaken in a crisis period, or by a foreign acquirer. In other words, the assumption that high-value acquisitions are similar across domestic and foreign acquirers appears to be borne out by the data.

\section{Conclusion}

This paper provides a simple analytical framework for assessing the acquirer-side effects of adverse aggregate financial shocks on the market for corporate control. We model two kinds of acquiring firms: those operating under financial constraints similar to target firms, and those that are financially unconstrained. We derive two hypotheses stating that financial crises have opposite effects on the acquisition behavior of these two groups: Acquisitions undertaken during financial crises feature smaller shares and are shorter lived for unconstrained acquirers, but are characterized by larger shares and are more persistent for constrained acquirers. Intuitively, financial crises induce a selection effect among constrained acquirers with only the most productive and liquid firms completing acquisitions. Interpreting constrained and unconstrained acquiring firms as domestic and foreign acquirers in a large dataset of emerging market acquisitions spanning the years 1990-2007, we provide evidence of an increase in the relative stakes acquired in domestic acquisitions, as well as a relatively lower divestiture rates domestic acquisitions in the crisis cohort, as predicted by the model.

It is worth stressing that our contrasting results for unconstrained (foreign) and constrained (domestic) acquisitions highlight the role of firm level borrowing constraints for firm acquisitions, which in our model comprise the only difference between firms, in determining which financially constrained firms remain active in the market for corporate control. It should be noted that this is a deliberate modelling choice, and done to demonstrate the effect we are after - the difference in the behavior of foreign and domestic firms when the latter are faced by financial shocks - most cleanly. Thus our results have mostly focussed on the comparative statics of a financial shock rather than the initial level differences in the variables of interest (such as shares acquired and divestiture rates), which could be due to differences in technology between foreign and domestic firms that are explicitly excluded in the model. It is therefore little surprising that our model empirically performs much better in explaining crisis-induced changes in 
acquired shares and divestiture than their level differences.

Our model has important macro-economic implications that are worth exploring. For example, the selection effects described in this paper have direct consequences for an economy's aggregate productivity. Since Joseph Schumpeter's classic work (Schumpeter, 1934), it is well understood that recessions or financial crises lead to higher average productivity through a so-called "cleansing" effect that forces the exit of the least productive firms. Our model suggests that such a cleansing effect might also be present in the market for corporate control, where it shifts resources towards the most productive M\&As. Since these M\&As are also shown to be longer lived, these effects are likely to endure beyond the financial crisis

itself. A careful analysis of these effects requires a dynamic model and is beyond the scope of this paper, but we already point towards selection effects that are likely to be critical in such a model.

The model also has a rich set of firm-level predictions regarding the joint distribution of productivity and financial liquidity for acquirers and targets that we do not test. Using firm level balance-sheet data from select EMEs to explore these predictions is a fruitful direction for future work. Also, while applied to the data in the context of EMEs, the model in this paper is equally applicable to acquisitions in developed markets, for which better quality and more extensive firm-level data exist, and where financial liquidity has also been shown to be important for the M\&A process (see Almeida, Campello and Hackbarth, 2011; Erel, Jang and Weisbach, 2014). The model can thus help guide future empirical work on the role of productivity and financial constraints in the market for corporate control in these countries. These and other investigations are left for future work.

\section{References}

Acharya, Viral V, Hyun Song Shin, and Tanju Yorulmazer. 2011a. "Crisis resolution and bank liquidity." Review of Financial studies, 24(6): 2166-2205.

Acharya, V. V., and S. Viswanathan. 2007. "Moral Hazard, Collateral and Liquidity." London Business School and Fuqua School of Business Working Paper.

Acharya, V.V., H. Shin, and T. Yorulmazer. 2011b. "Fire-sale FDI." Korean Economic Review, 27(2): 163202.

Acharya, V. V., H. S. Shin, and T. Yorulmazer. 2008. "Banks's Choice of Liquidity: The Role of Fire Sales and Entry." London Business School Working Paper.

Aguiar, M., and G. Gopinath. 2005. "Fire-Sale Foreign Direct Investment and Liquidity Crises." Review of Economics and Statistics, 87: 439-452. 
Albuquerque, Rui, and Hugo A. Hopenhayn. 2004. "Optimal Lending Contracts and Firm Dynamics." The Review of Economic Studies, 71(2): 285-315.

Almeida, Heitor, Murillo Campello, and Dirk Hackbarth. 2011. "Liquidity Mergers." fournal of Financial Economics, 102(3): 526-558.

Alquist, Ron, Nicolas Berman, Rahul Mukherjee, and Linda Tesar. 2017. "Liquidity-Driven FDI." NBER Working Paper No.

Alquist, Ron, Rahul Mukherjee, and Linda Tesar. 2016. "Fire Sale FDI or Business as Usual?” fournal of International Economics, 98: 93-113.

Ang, James S, Rebel A Cole, and James Wuh Lin. 2000. “Agency costs and ownership structure." the Journal of Finance, 55(1): 81-106.

Asiedu, Elizabeth, and Hadi Salehi Esfahani. 2001. "Ownership Structure in Foreign Direct Investment Projects." Review of Economics and Statistics, 83(4): 647-662.

Bergh, D. D. 1997. "Predicting Divestiture of Unrelated Acquisitions: An Integrative Model of Ex Ante Conditions." Strategic Management fournal, 18: 715-731.

Bernanke, Ben, and Mark Gertler. 1989. "Agency Costs, Net Worth, and Business Fluctuations." The American Economic Review, 79(1): 14-31.

Bris, Arturo, and Christos Cabolis. 2008. "The value of investor protection: Firm evidence from crossborder mergers." Review of Financial Studies, 21(2): 605-648.

Brooks, Wyatt, and Alessandro Dovis. 2013. "Credit Market Frictions and Trade Liberalization."

Brown, C.O., and I.S. Dinc. 2011. "Too Many to Fail? Evidence of Regulatory Forbearance When the Banking Sector is Weak." Review of Financial Studies, 24(4).

Buera, Francisco J, Joseph P Kaboski, and Yongseok Shin. 2011. "Finance and Development: A Tale of Two Sectors." American Economic Review, 101(5): 1964-2002.

Caballero, Ricardo J, and Mohamad L Hammour. 1996. "On the Timing and Efficiency of Creative Destruction." The Quarterly fournal of Economics, 111(3): 805-52.

Chari, A., P. P. Ouimet, and L. L. Tesar. 2010. “The Value of Control in Emerging Markets." Review of Financial Studies, 23(4).

Cui, Wei. 2014. "Delayed Capital Reallocation." Available at SSRN 2482431. 
Di Giovanni, Julian, Andrei A Levchenko, and Romain Ranciere. 2011. "Power laws in firm size and openness to trade: Measurement and implications." fournal of International Economics, 85(1): 42-52.

Eisfeldt, Andrea L, and Adriano A Rampini. 2006. "Capital reallocation and liquidity." fournal of monetary Economics, 53(3): 369-399.

Erel, Isil, Yeejin Jang, and Michael S Weisbach. 2014. "Do Acquisitions Relieve Target Firms Financial Constraints?" The fournal of Finance.

Foster, Lucia, John Haltiwanger, and Chad Syverson. 2008. "Reallocation, Firm Turnover, and Efficiency: Selection on Productivity or Profitability?” American Economic Review, 98(1): 394-425.

Froot, Kenneth A. 1991. "Exchange Rates and Foreign Direct Investment: An Imperfect Capital Markets Approach.” The Quarterly fournal of Economics.

Hanousek, Jan, and Evžen Kočenda. 2017. "FDI and Ownership in Czech Firms: Pre-and Post-crisis Efficiency." Economics of European Crises and Emerging Markets, 121-145. Springer.

Holtz-Eakin, Douglas, David Joulfaian, and Harvey S Rosen. 1994. "Sticking it Out: Entrepreneurial Survival and Liquidity Constraints.” Journal of Political Economy, 53-75.

Hoskisson, Robert E, Richard A Johnson, and Douglas D Moesel. 1994. "Corporate divestiture intensity in restructuring firms: Effects of governance, strategy, and performance." Academy of Management journal, 37(5): 1207-1251.

Kalbfleisch, J. D., and R. L. Prentice. 1980. The Statistical Analysis of Failure Time Data. New York:Wiley.

Kaplan, S. N., and M. S. Weisbach. 1992. "The Success of Acquisitions: Evidence from Divestitures." fournal of Finance, 47: 107-138.

Kehoe, Patrick J., and Fabrizio Perri. 2002. "International Business Cycles with Endogenous Incomplete Markets." Econometrica, 70(3): 907-928.

Kiyotaki, Nobuhiro, and John Moore. 1997. "Credit Cycles." The fournal of Political Economy, 105(2): 211-248.

Laeven, L., and F. Valencia. 2010. "Resolution of Banking Crises: The Good, the Bad, and the Ugly." IMF Working Paper, 10/146.

Lee, Donghun, and Ravi Madhavan. 2010. "Divestiture and firm performance: A meta-analysis.” Fournal of Management, 36(6): 1345-1371. 
Melitz, Marc J. 2003. "The impact of trade on intra-industry reallocations and aggregate industry productivity." Econometrica, 71(6): 1695-1725.

Moeller, S.B., F.P. Schlingemann, and R.N. Stulz. 2005. "Wealth Destruction on a Massive Scale? A Study of Acquiring-Firm Returns in the Recent Merger Wave." fournal of Finance, 60: 757-782.

Oberfield, Ezra. 2013. "Productivity and misallocation during a crisis: Evidence from the Chilean crisis of 1982." Review of Economic Dynamics, 16(1): 100-119.

Osotimehin, Sophie, and Francesco Pappadà. 2015. "Credit frictions and the cleansing effect of recessions." The Economic fournal.

Ravenscraft, D. J., and F. M. Scherer. 1991. "Divisional Sell-Off: A Hazard Function Analysis.” Managerial and Decision Economics, 12: 429-438.

Reinhart, C. M., and K. S. Rogoff. 2009. This Time is Different: Eight Centuries of Financial Folly. Princeton, N.J:Princeton University Press.

Rhodes-Kropf, Matthew, and David T Robinson. 2008. "The market for mergers and the boundaries of the firm." The fournal of Finance, 63(3): 1169-1211.

Sandleris, Guido, and Mark LJ Wright. 2014. "The costs of financial crises: Resource misallocation, productivity, and welfare in the 2001 argentine crisis." The Scandinavian fournal of Economics, 116(1): 87127.

Schumpeter, Joseph Alois. 1934. The theory of economic development: An inquiry into profits, capital, credit, interest, and the business cycle. Vol. 55, Transaction publishers.

UNCTAD. 2015. "World Investment Report."

Wang, Jian, and Xiao Wang. 2015. "Benefits of Foreign Ownership: Evidence from Foreign Direct Investment in China." The Journal of International Economics.

Zhu, PengCheng, Vijay Jog, and Isaac Otchere. 2011. "Partial acquisitions in emerging markets: A test of the strategic market entry and corporate control hypotheses." fournal of Corporate Finance, 17(2): 288-305. 